\title{
Article
}

\section{A Review of Wearable Sensor Systems to Monitor Plantar Loading in the Assessment of Diabetic Foot Ulcers}

Wang, Lefan, Jones, Dominic, Chapman, Graham, Siddle, Heidi J, Russell, David A, Alazmani, Ali and Culmer, Peter

Available at http://clok.uclan.ac.uk/30648/

Wang, Lefan, Jones, Dominic, Chapman, Graham ORCID: 0000-0003-39836641, Siddle, Heidi J, Russell, David A, Alazmani, Ali and Culmer, Peter (2019) A Review of Wearable Sensor Systems to Monitor Plantar Loading in the Assessment of Diabetic Foot Ulcers. IEEE Transactions on Biomedical Engineering (TBME) . ISSN 0018-9294

It is advisable to refer to the publisher's version if you intend to cite from the work. http://dx.doi.org/10.1109/TBME.2019.2953630

For more information about UCLan's research in this area go to http://www.uclan.ac.uk/researchgroups/ and search for <name of research Group>.

For information about Research generally at UCLan please go to http://www.uclan.ac.uk/research/

All outputs in CLoK are protected by Intellectual Property Rights law, including Copyright law. Copyright, IPR and Moral Rights for the works on this site are retained by the individual authors and/or other copyright owners. Terms and conditions for use of this material are defined in the policies page. 


\title{
A Review of Wearable Sensor Systems to Monitor Plantar Loading in the Assessment of Diabetic Foot Ulcers
}

\author{
Lefan Wang, Dominic Jones, Graham J Chapman, Heidi J Siddle, David A Russell, Ali Alazmani, and \\ Peter Culmer
}

\begin{abstract}
Diabetes is highly prevalent throughout the world and imposes a high economic cost on countries at all income levels. Foot ulceration is one devastating consequence of diabetes, which can lead to amputation and mortality. Clinical assessment of diabetic foot ulcer (DFU) is currently subjective and limited, impeding effective diagnosis, treatment and prevention. Studies have shown that pressure and shear stress at the plantar surface of the foot plays an important role in the development of DFUs. Quantification of these could provide an improved means of assessment of the risk of developing DFUs. However, commercially-available sensing technology can only measure plantar pressures, neglecting shear stresses and thus limiting their clinical utility. Research into new sensor systems which can measure both plantar pressure and shear stresses are thus critical.

Our aim in this paper is to provide the reader with an overview of recent advances in plantar pressure and stress sensing and offer insights into future needs in this critical area of healthcare. Firstly, we use current clinical understanding as the basis to define requirements for wearable sensor systems capable of assessing DFU. Secondly, we review the fundamental sensing technologies employed in this field and investigate the capabilities of the resultant wearable systems, including both commercial and research-grade equipment. Finally, we discuss research trends, ongoing challenges and future opportunities for improved sensing technologies to monitor plantar loading in the diabetic foot.
\end{abstract}

Index Terms - Diabetes; Foot ulceration; Instrumented footwear devices; Insole systems; Plantar pressure distribution; Plantar shear stress.

\section{INTRODUCTION}

$\mathrm{D}$ iabetes is a major health-related problem which has become a global health crisis of the $21^{\text {st }}$ century. The prevalence of diabetes has dramatically increased within a short time due to factors including unhealthy lifestyles and rapid urbanization. The International Diabetes Federation reported that there are 425 million adults with diabetes worldwide in

This work was supported by the UK EPSRC under Grant EP/R041776/1.

L. Wang, D. Jones, A. Alazmani, and P. Culmer work in the School of Mechanical Engineering, University of Leeds, Leeds LS2 9JT, UK. (e-mail: L.Wang6@leeds.ac.uk, D.P.Jones@leeds.ac.uk, A.Alazmani@leeds.ac.uk, P.R.Culmer@leeds.ac.uk).

G. J. Chapman works in the School of Health Sciences, University of Central Lancashire, Brook Building (BB132), Preston PR1 2HE, UK (email: GChapman2@uclan.ac.uk), the Institute of Rheumatic and Musculoskeletal Medicine, University of Leeds, Leeds, UK and NIHR Leeds Biomedical Research Centre, Leeds, UK
2017, 10 million more than in 2015. If the trend continues, the number of adults living with diabetes will grow to 629 million in 2045 [1].

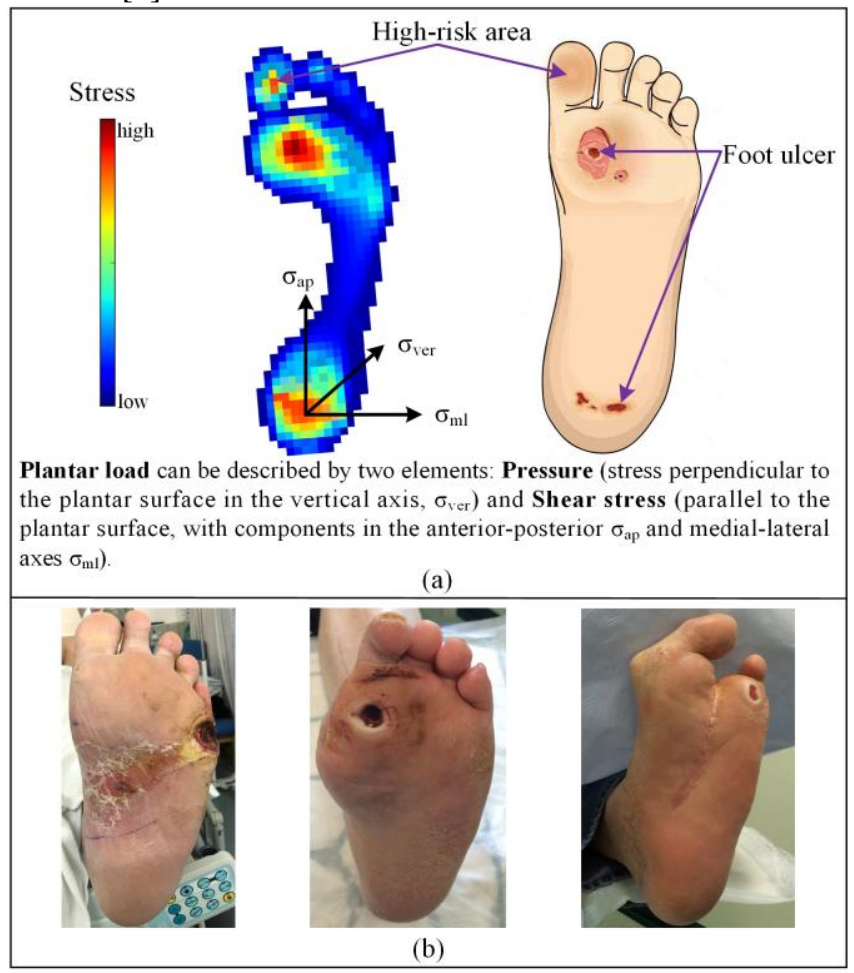

Figure 1. (a) Plantar load distribution across a foot with diabetic ulcer; (b) examples of diabetic foot ulcers and resulting deformity and minor amputation.

Foot complications are among the most common and devastating complications of diabetes, particularly diabetic foot ulcers (DFUs). Population-based studies have reported the annual incidence of foot ulceration among people with diabetes to be $2-3 \%$ [1]-[8]. About $15 \%$ of the people with diabetes are estimated to suffer from DFU during their lifetime [9]. Once

H. J. Siddle works in the Leeds Institute of Rheumatic and Musculoskeletal Medicine, University of Leeds, Leeds, UK and Podiatry Department, Leeds Teaching Hospitals NHS Trust, Leeds, UK (e-mail: H.Siddle@ leeds.ac.uk).

D. A. Russell works in the Leeds Institute of Cardiovascular and Metabolic Medicine, LIGHT Laboratories, University of Leeds, 6 Clarendon Way, Leeds LS2 9NL, UK and Leeds Diabetes Limb Salvage Service, Leeds Teaching Hospitals NHS Trust, Beckett Street, Leeds LS9 7TF, UK (e-mail: davidrussell1@nhs.net). 
developed, foot ulceration may take several weeks or months to heal, or even fail to heal at all, despite medical treatment [10]. In addition, DFUs frequently recur; approximately $40 \%$ of patients experience recurrence within one year and $60 \%$ within three years [11]. DFUs lead to infection in over half of cases [12] which brings an increased risk of lower-limb amputation (see Figure 1(b)) and is the leading cause of mortality for people with diabetes (DFU brings a 2.5 fold increase in risk of death over 5 years [13]). DFUs not only decrease quality of life of the individual, but also impose a substantial economic and societal impact in the form of increased hospitalization rates, cost of care, and reduced mobility in patients. In 2014-2015, the National Health Service (NHS) in England spent $£ 1.13$ billion, equivalent $0.83 \%$ of the entire NHS budget, on the treatment of DFUs [14]. Generally, the health expenditures of people with DFUs are 5 times higher than those of people with diabetes but without foot ulceration [1].

DFUs form as a consequence of diabetes-induced damage to the nervous and vascular systems within the foot. As illustrated in Figure 1, this manifests as foot deformity from abnormal muscle function (e.g. claw feet and prominent metatarsal heads) leading to abnormal plantar stresses [15]. Initial clinical studies explored the links between plantar pressure and DFU formation. However, recent clinical evidence indicates that the situation is more complex and that plantar pressure in isolation may be ineffective for predicting DFU formation [16], [17] with a key study finding that only $35 \%$ of DFUs occurred at highpressure areas [18]. Abnormal plantar shear stress has been shown as an important factor in the development of DFUs [11], [19]-[24]. A seminal study by Yavuz et al. showed that $50 \%$ of DFUs developed at plantar locations with elevated shear stress [22] and accordingly recommended monitoring both plantar pressure and shear stress for a more effective management of DFUs. This is supported by evidence that neuropathic ulcers commonly occur through hyperkeratotic lesions caused by excessive foot friction (induced by shear stress) [21], [25]. As a result of abnormal plantar loading, repetitive moderate stress injury causes tissue inflammation and formation of hyperkeratotic, hard skin (callus). In the absence of protective sensation in the feet due to the nerve damage (neuropathy), compensatory mechanisms resulting from pain stimuli such as limping or gait modification to redistribute pressure in the foot fail to occur. Continued inflammation causes enzymatic autolysis with tissue breakdown and ulceration [26]. DFU healing will not occur until therapeutic footwear has been implemented to redistribute load away from the site of the ulcer (UK National Institute for Health and Care Excellence guidelines [27]).

The major ambition of clinical practice for DFU is to prevent ulcer formation through early identification and intervention. This reflects the challenge, and healthcare costs, associated with effective treatment once an ulcer is present. Regular foot assessment and education are recommended for people with diabetes, a process which is typically stratified according to the risk of ulcer development [27]. Current risk assessment is clinical and subjective, assessing presence of neuropathy, deformity of the foot and presence of callus as surrogate markers of high plantar load, with recommendation for therapeutic footwear in those at moderate or high risk [28]. Use of generic shear reducing insoles has been shown to reduce incidence of ulcer formation in high risk patients [29]. Previous studies have shown bespoke therapeutic footwear modified to achieve plantar pressures to a pre-specified target measurement are more effective than bespoke footwear provided that patients are concordant with their use [30]. Thus any device that allows in-shoe assessment of plantar pressure and shear stress both with and without offloading insoles is likely to reduce incidence of ulceration. However, such a device would need to be simple and quick to use if it is to be adopted into routine clinical practice.

If DFUs occur, typical clinical treatment includes wound debridement and dressing, offloading, controlling foot infection and managing foot ischemia [27]. Of these interventions, the use of offloading techniques is considered a key intervention for the management of DFUs in patients with neuropathy [19], [31]-[33] and numerous studies have shown that appropriate pressure offloading can promote enhanced DFU healing [32], [34]-[36]. Offloading strategies seek to reduce and/or redistribute plantar pressure through interventions such as total contact casts, removable cast walkers, temporary forefoot/heel off-loading shoes and orthotic insoles [31]. In addition, Lavery et al. [29] found that people with diabetes wearing insoles which reduced both plantar pressure and shear stress were approximately 3.5 times less likely to develop foot ulceration than the traditional insole group.

The success of these interventions is dependent on the provision of clinically relevant information to ensure timely intervention, and patient concordance (i.e. actually wearing the offloading device). As such it is evident that there is a need for improved and clinically accessible measurement systems to monitor tissue health in the feet of people with diabetes, in particular at the plantar surface on which DFUs form. To date, devices have been proposed to measure a variety of parameters including temperature [37], [38], $\mathrm{pH}$ values [39], humidity [40], and pressure/stress [41]-[43]. Among these, the measurement of plantar loading on the diabetic foot is most developed due to its strong association with ulcer formation and the efficacy of plantar offloading interventions. A variety of underlying sensor technologies have been explored to obtain measurements of plantar stress in healthy and diseased feet. Systems can be broadly divided into sensing platforms (with a similar form to force plates in gait labs, allowing static and limited dynamic measurements of 1-2 stance phases) and wearable sensory systems, attached by some means to the foot (often as an insole worn in the shoe, capable of measuring both static and dynamic motion across multiple stance phases). These capabilities have utility in both fundamental research (e.g. to improve understanding of foot biomechanics or inform innovations in orthotics) and clinical practice (to guide screening, assessment and patient specific treatment).

Previous reviews in this area have examined tactile sensor technology [44], [45], use of plantar pressure to diagnose disease and gait disorders [46], [47], physiological aspects of DFU formation [48] and plantar pressure measurement in general terms [49]-[52]. In this paper, we seek to build on these 
works, providing an engineering perspective on recent developments of wearable technology for plantar stress measurement in the diabetic foot. Section II presents the requirements for DFU measurements. Section III reviews the fundamental sensing techniques which have been developed or applied in this area. Section IV focuses on their application in instrumented wearable footwear, considering both commercial and research systems. Sections $\mathrm{V}$ then discusses the development trends and the challenges facing wearable plantar measurement systems, drawing on recent research to provide recommendations for future developments in the field. Finally, our conclusions are presented in section VI.

\section{REQUIREMENTS FOR WEARABLE LOAD SENSING OF DIABETIC FOOT ULCERS}

Our understanding of the mechanics of DFU formation has developed significantly over recent years. This provides a valuable evidence base against which to define requirements for wearable load-based sensing systems that can effectively assess the risk and impact of DFUs.

Measurement Capabilities: As discussed above, research indicates that it is important to measure pressure and shear stress at the plantar surface [12, 19-24]. Therefore, at each desired measurement location, multiaxial load sensing should be employed to record both plantar pressure and shear stress. Ideally, since little known of the properties of plantar shear stress, this would constitute a triaxial load measurement such that both perpendicular components of shear (see Figure 1(a)) could be monitored independently.

The available information on the plantar loading of people with diabetes help inform the required measurement range. Lord and Hosein [53] reported a maximum pressure of $273 \mathrm{kPa}$ occurring at the $2^{\text {nd }}$ metatarsal head $(\mathrm{MTH})$ and a maximum shear stress of $72.7 \mathrm{kPa}$ at the $1^{\text {st }} \mathrm{MTH}$. The most complete has been developed using the custom built Cleveland Clinic Plate which records plantar pressure and shear measures across an array of 80 strain sensors [17], [54]. Yavuz et al. used this system in people with diabetic neuropathy, finding peak pressures of $484.4 \mathrm{kPa}$ occurring at the central forefoot and a maximum shear of $77.9 \mathrm{kPa}$ under the hallux [17]. In 2017 they extended this work in a study of nine participants with a history of DFU, reporting peak pressures of $738.6 \mathrm{kPa}$ and peak shear stresses of $135.3 \mathrm{kPa}$ [55]. According to these results, a measurement range of $>=740 \mathrm{kPa}$ for pressure and $>=140 \mathrm{kPa}$ for shear detection is advised.

Sensor Distribution and Location: Placement of sensors relative to the plantar surface is an important factor in achieving clinically useful measurements. Studies show that DFUs can occur in a wide variety of locations across the plantar surface and that these locations can be unpredictable due to offloading interventions [56]. Consequently, it is pragmatic to distribute sensors across the entire plantar surface unless a specific region of the plantar surface is the focus of assessment (e.g. a metatarsal head).

The proximity of each sensor to the foot's plantar surface is linked to measurement quality. The presence of intermediate layers (e.g. shoe soles) between the foot and sensor interface will contribute noise and/or additional physical dynamics to the system. This could lead to a poor signal-to-noise ratio, attenuation of high frequency temporal characteristics (due to mechanical damping) or spatial averaging through distribution of stresses [52]. Accordingly it is advisable to locate sensors close to the plantar surface to minimize these factors.

Spatial Resolution: The number of sensing elements and their respective size are interlinked aspects of the measurement system. For a given coverage area (e.g. the plantar surface) the size of the sensor element defines the maximum spatial resolution which can be achieved. In general, smaller sensors are preferable since they permit higher spatial resolutions [57]. However, integrating large numbers of sensors into a measurement system brings associated demands in interface electronics, data processing and data management. Razian and Pepper [58] recommended the surface size of the sensors should not be larger than $10 \mathrm{~mm} \times 10 \mathrm{~mm}$, particularly for the sensors under the toe and the metatarsal regions. Davis et al. [59] claimed that the sensor size should be no more than $6.36 \mathrm{~mm} \times$ $6.18 \mathrm{~mm}$ to avoid underestimating the plantar pressure. Urry [50] stated that in contemporary plantar stress measurement systems, the sensor's active surface area should be $5 \mathrm{~mm} \times 5$ $\mathrm{mm}$ or less. Berki and Davis [60] suggested that the sensors with dimensions $4.8 \mathrm{~mm} \times 4.8 \mathrm{~mm}$ or less would reliably capture information of both plantar pressure and shear stress. Considering these factors, we suggest the sensor's active surface area should not exceed $10 \mathrm{~mm} \times 10 \mathrm{~mm}$ in a wearable plantar load measurement system.

Sampling Rate: The majority of commercially available plantar pressure measurement devices operate between 50$100 \mathrm{~Hz}$ [51], [52]. These rates are appropriate for capturing the plantar pressure dynamics associated with typical walking patterns and accordingly the system's sampling rate (e.g. considering all sensors) should be no less than $50 \mathrm{~Hz}$.

Clinical Implementation: For a DFU measurement system to have clinical efficacy it is essential to consider implementation factors which relate to end-users of the technology (notably clinicians and people at risk of DFUs) and the intended use cases. Research-grade systems (used in controlled laboratory environments) must enable researchers to access detailed measurement data for further study. Clinical systems (used in clinical settings) must be capable of being fitted, set up and operated quickly and easily to meet the demands of time and resource-constrained healthcare systems. Data from the system must be processed into a valuable form for the clinical end-user. For example, highlighting to a clinician where a patient's plantar response is changing from the healthy 'norm' thus enabling targeted early intervention to prevent DFU formation. Cleaning and hygiene control between users is also an important consideration in this context. Consumer-grade systems (used in the varying environments of daily life) also need to be quick and easy to fit (to minimize their impact on the user's daily routine) and in a reliable manner (to ensure measurements are consistent over repeated use). Furthermore, they should process and display information pertinent to users, empowering them with self-management of their condition. For instance, generating warning signals when 
stresses exceed 'safe' thresholds. These feedback mechanisms have the potential to help identify and avoid adverse behavior to reduce the risk of DFUs.

Specific user requirements associated with these use cases may vary but some generalizations can be made in terms of technical requirements, as summarized in Table 1. Additionally, a system to monitor DFUs should not affect natural gait, cause discomfort, or place the foot at risk of any further damage. Accordingly, the system should aim to be lightweight, small in overall size and specifically for sensing elements which are low-profile and physically robust to the challenging load environment under which they are placed. It is also vital that measurements from the system remain repeatable under different operating conditions (e.g. during bending or changing humidity) and over extended use. Finally, to enable freedom of movement (to promote natural gait), it is desirable for the system to be wearable and wireless (thus avoiding the need of tethering for power or communications), aspects which are considered in detail in recent reviews [61], [62].

TABLE 1. SUMMARY OF THE MAIN REQUIREMENTS FOR MEASURING PLANTAR

\begin{tabular}{lll}
\multicolumn{2}{c}{ LOAD } & $>740 \mathrm{kPa}$ \\
Measuring capability & $\begin{array}{l}\text { Pressure } \\
\text { Shear stress }\end{array}$ & $>140 \mathrm{kPa}$ \\
Spatial resolution / & $<=10 \mathrm{~mm} \times 10 \mathrm{~mm}$ \\
sensor's active surface & $>=50 \mathrm{~Hz}$ \\
Sampling rate & (Generally) cover the entire plantar surface \\
Sensor distribution & As close to the plantar surface as possible \\
Sensor location &
\end{tabular}

\section{SENSING TECHNOLOGIES FOR PLANTAR STRESS MEASUREMENT}

A variety of sensing technologies have been proposed to measure loading at the plantar surface. Commonly used sensing techniques within research settings are based on a number of methods, including resistive, capacitive, inductive, piezoelectric, and optical fibre. Among these sensing methods, the majority have a single measurement axis, focused on detection of plantar pressure while relatively few are designed with multiple measurement axes capable of monitoring both pressure and shear stress. In this section, we give a brief review of these sensing methods.

\section{A. Resistive sensors}

Resistive sensors respond to the mechanical deformation with a variation of electrical resistance. This is the most widely used thin-film sensor technology for pressure measurement due to its simple operation, ability to form a sensor array, and low cost. In 2011 Wang et al. [63] designed a flexible fabric pressure sensor by sandwiching a conductive coating of carbon black/silicone composites between two tooth-structured conversion layers, as illustrated in Figure 2(a). Application of pressure causes deformation of the sensing fabric and so the electrical resistance is changed. The sensor can measure a pressure range of 0 to $2000 \mathrm{kPa}$. In 2012 the researchers then used 8 of these fabric sensors integrated with an insole to measure the plantar pressure distribution of people with diabetes [64]. In 2015 Lin et al. [65] implemented a textile pressure sensor using knitting technique and a sensing matrix was integrated with a sock for measuring pressure in 2017 [41].
In 2012 Gerlach et al. [66] used a different approach, exploiting materials research to use a composite of multiwall carbon nanotube (CNT) and polydimethylsiloxane (PDMS) to make a single axis pressure sensor for plantar pressure measurement. This work was expanded in 2015 to a sensing matrix capable of tracking the pressure distribution across the entire plantar surface [43]. The sensing matrix, as shown in Figure 2(b), was arranged in rows and columns with interconnecting electrodes, allowing the resistance of each node to be individually measured, with changes occurring as the CNT-PDMS composite was compressed under pressure.

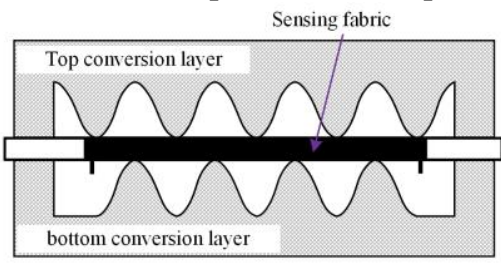

(a)
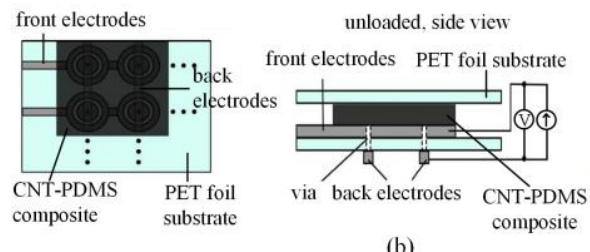

(b)


electrical contact
Figure 2. Resistive sensors for pressure measurement. (a) fabric pressure sensor [63]; (b) CNT-PDMS-composite sensing matrix [43].

Several flexible resistive pressure sensors are commercially available. The FlexiForce ${ }^{\circledR}$ sensors manufactured by Tekscan, Inc. [67] provide thin-film pressure sensing and have been widely used to measure plantar pressure [68]-[70]. For instance, Zabihollahy et al. [68] used a FlexiForce ${ }^{\circledR}$ sensor to monitor the pressure at the heel while Bernard et al. [69] employed three sensors to detect the pressure at the hallux, the $1^{\text {st }}$ MTH and the heel. The Force Sensing Resistor ${ }^{\circledR}$ (FSR) from Interlink Electronics Inc. provides similar capabilities [71] and has also been used to investigate plantar pressure. Pfaffen et al. [72] integrated 16 FSR sensors into a shoe sole for tracking foot pressure distributions and Benbakhti et al. [73] developed an insole-based system containing six FSR sensors.

In addition to pressure sensing, resistance-based sensors have also been developed for shear measurement, typically based on the magneto-resistive effect. In 1980 Tappin et al. [74] developed the first magneto-resistive sensor for plantar shear stress measurements. The uniaxial shear sensor consisted of two thin stainless steel discs ( $\varnothing 15.96 \mathrm{~mm}$ ) held together by a silicon layer; one disc was magnetised and the other connected to a magneto-resistor. This arrangement was used as two arms of a bridge circuit which provided a voltage change when shear stress was applied that changed the disc overlap. Although each sensor could only determine a single axis of shear, the technology was combined with commercial pressure sensors to measure loading at 6 plantar locations in a study with healthy people [75]. The system was then used in pioneering work to investigate plantar load patterns of people with DFUs in 1983 [24]. Using the same magneto-resistive principle, in 1992 Lord et al. [76] developed a shear stress sensor capable of simultaneously measuring shear in two orthogonal directions. In 2000 the system was used in seminal work to study the in- 
shoe shear stress distribution of nine asymptomatic adults [77] and six patients who had a history of DFU [53]. Measurements were obtained from three shear sensors (each being $\varnothing 15.96 \mathrm{~mm}$ $\times 4 \mathrm{~mm}$ ) located either under the heel, $1^{\text {st }}$ and $3^{\text {rd }}$ MTHs or under the heel, $2^{\text {nd }}$ and $4^{\text {th }}$ MTHs.

Resistive sensors have many virtues for plantar load sensing in that they are typically low-cost, require minimal interface electronics and have low sensitivity to electromagnetic interference. However, they can suffer from low repeatability [78], [79] and their use in multiaxial measurements has been limited.

\section{B. Capacitive sensors}

A capacitive pressure sensor is typically composed of two electrical conducting plates separated by a dielectric layer (e.g. air, mica, ceramic, PDMS, or other insulating material). When loaded, the gap between the two plates is decreased, resulting in a measureable capacitance change.

In 2012 Lei et al. [80] developed a capacitive pressure sensor for measuring plantar load shown in Figure 3. The sensor consisted of four layers: a raised 'bump' layer, a top electrode, a PDMS dielectric layer, and a bottom layer with four electrodes. This forms four independent capacitive sensing circuits which are averaged to enable robust pressure measurement up to $945 \mathrm{kPa}$, even in the presence of loads causing non-uniform deformation to the dielectric layer.

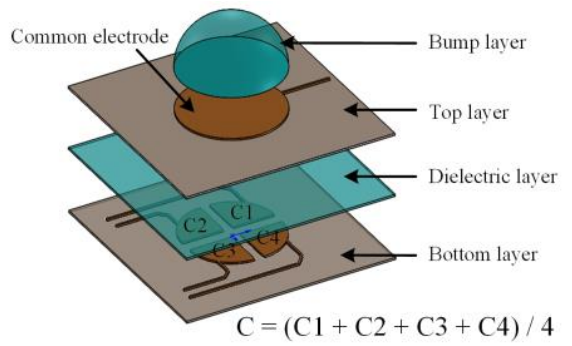

Figure 3. Structure of the capacitive pressure sensor [80].

In 2015 Motha et al. [81] used a different approach to develop a printable capacitive sensor which exploits a change in the relative permittivity of the dielectric when compressed. The system was integrated into a rubber insole and achieved a pressure sensing range of $450 \mathrm{kPa}$.

Many recent studies on capacitive sensing technology have focused on the development of multiaxial (typically triaxial) force sensors. In general, these sensors embed four capacitive elements which can be used to obtain normal and shear forces through selective decoupling of the output signals. Using this approach, in 2013 Dobrzynska and Gijs [82] developed a flexible triaxial force sensor, shown in Figure 4, employing a silicone dielectric. This sensor was capable of measuring load in each axis up to $14 \mathrm{~N}$ (equivalent to $220 \mathrm{kPa}$ ), offering an appropriate range for plantar shear stress measurement.

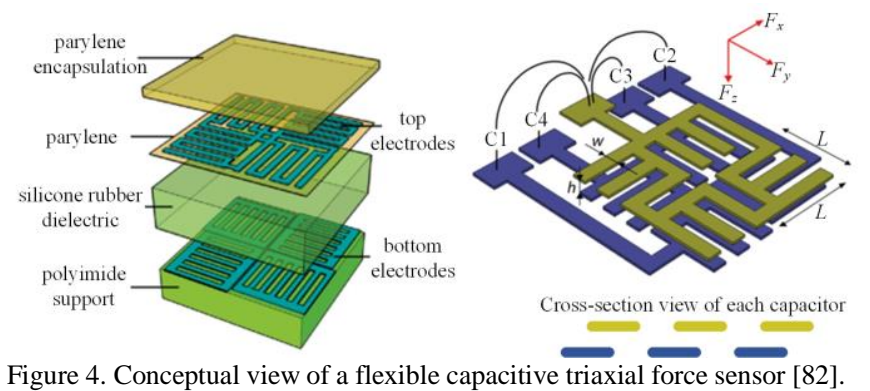

Similar approaches have been used by a range of researchers seeking to develop triaxial capacitive force sensors which are flexible. Predominantly these have been motivated by the need for improved tactile sensing in robotics which is reflected in lower sensing ranges but higher sensitivities than those described above. For instance, in 2015 Liang et al. [83] implemented a triaxial force sensing array in which each sensor unit has a dimension of $4.0 \mathrm{~mm} \times 4.0 \mathrm{~mm} \times 1.1 \mathrm{~mm}$ and provides a measurement range of $0.5 \mathrm{~N}$ and $4 \mathrm{~N}$ (equivalent to $31 \mathrm{kPa}$ and $250 \mathrm{kPa}$ ) for shear and normal load, respectively. Further notable developments include an $8 \times 8$ triaxial force sensing array proposed by Lee et al. in 2008 [84] with a fullscale range of $10 \mathrm{mN}$ (corresponding to $131 \mathrm{kPa}$ ) in each axis, and a precision force sensor reported by Charalambids and Bergbreiter in 2015 [85] which can measure normal force from $190 \mathrm{mN}$ to $8 \mathrm{~N}$ (equivalent to $85 \mathrm{~Pa}-3555 \mathrm{kPa}$ ) and shear force from $50 \mathrm{mN}$ to $2 \mathrm{~N}$ (equal to $22 \mathrm{~Pa}-888 \mathrm{kPa}$ ).

Research attention has brought significant advances in capacitive force sensors, particularly in the development of multiaxial sensing arrays. Many of these systems have been designed for tactile applications and as such have a limited measurement range for monitoring plantar load. However, they are also flexible in configuration and typically provide higher repeatability in comparison to resistive force sensors [86], making them a compelling technology for this application.

\section{Inductive sensors}

An inductive force sensor works on the principle of proximity, capable of detecting metallic objects without touching them. A coil and an oscillator are generally used to create an electromagnetic field surrounding a target conductor. The movement of the target caused a dampening change of the source induction field, leading to a variation of the oscillation amplitude.

In 1992 an early example of this approach was used to measure 3D displacement [87]. Extending this principle, in 2012 Wattanasarn et al. [88] designed a 3D flexible force sensor which consisted of four layers: a contact 'bump', detection coil, spacer and four excitation coils (see Figure 5(a)). In the unloaded state, the four detection coils produce the same output voltage. On application of load, the detection coil is displaced, resulting in differential voltage changes between the excitation coils. These can be selectively decoupled and used to calculate the applied load in a similar way to that used for triaxial capacitive sensors. In this design, each planar coil only had four turns, which made the sensor compact $(7.2 \mathrm{~mm} \times 7.2 \mathrm{~mm} \times 2.5$ $\mathrm{mm}$ ) but this inevitably compromised overall sensor performance including resolution and sensitivity. 


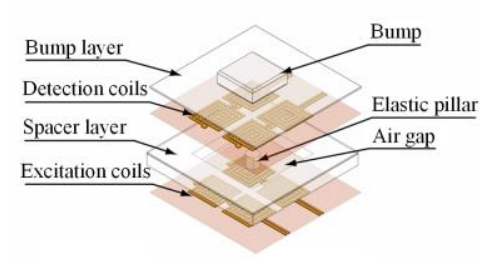

(a)



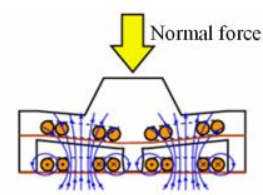

(c)

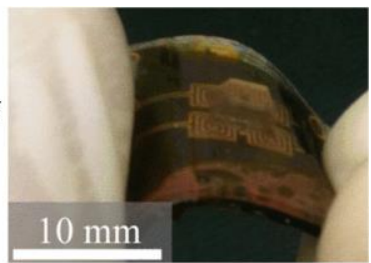

(b)

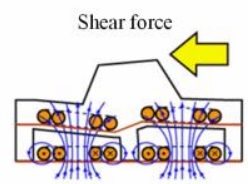

Figure 5. 3D electromagnetic induction sensor [88]. (a) Sensor structure; (b) sensor prototype; (c) side views of the mechanical deformation diagram of the sensor: without load, under normal force, and under a shear force.

In $2015 \mathrm{Du}$ et al. [89] used a variation of this method, exploiting the mechanism of eddy current effects to produce an inductive sensor capable of measuring both normal and shear force. As illustrated in Figure 6(a), the sensor consisted of three spiral-wound planar sensing coils, four rubber blocks fixed at the corners of the substrate, and a stainless steel plate. Each powered sensing coil generates a magnetic field, inducing an eddy current in the steel plate which in turn causes a variation in each coil's inductance. The inductance variations are dependent on the overlap and separation between coil and plate, hence measurement of the individual coil inductances is used to determine the applied load. The sensor was used to successfully measure plantar loads on the foot during normal gait but was greatly limited by the high spatial resolution in which each sensor has a dimension of $76.2 \mathrm{~mm} \times 76.2 \mathrm{~mm} \times 22 \mathrm{~mm}$.

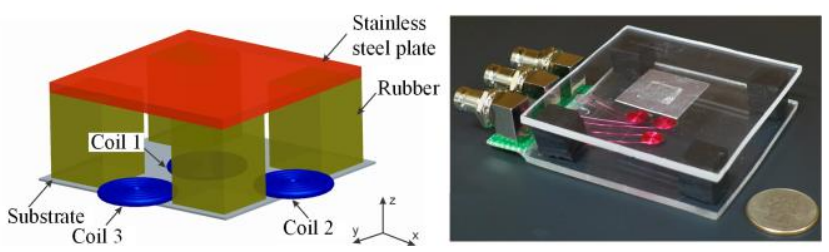

(a)

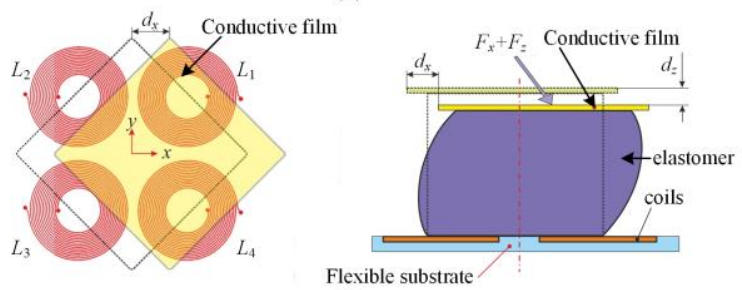

(b)

Figure 6. (a) Schematic and prototype of a three-coil inductive force sensor [89]; (b) Triaxial soft inductive force sensor [90].

In 2018 Wang et al. [90] used a similar approach to design a triaxial inductive sensor based on eddy current detection, achieving a significantly smaller footprint $(15 \mathrm{~mm} \times 15 \mathrm{~mm} \times$ $3 \mathrm{~mm}$ ). As shown in Figure 6(b), the sensor was composed of four sensing coils printed on a single substrate together with a conductive aluminum film connected together by an elastomer. This flexible sensor features a high measurement resolution of $0.3 \mathrm{mN}$ although the range is limited to $13 \mathrm{~N}(66 \mathrm{kPa})$ and 1.4 $\mathrm{N}$ (7 kPa) for normal and shear load, respectively, due to use of

a soft elastomeric layer. In 2019 Yeh and Fang [91] made further advances in miniaturizing this form of sensor using a standard CMOS fabrication technique. This precision manufacturing process enabled a form-factor of $2.8 \mathrm{~mm} \times 2.0$ $\mathrm{mm}$ with a measurement range of $20 \mathrm{~N}$ (normal force) and $4 \mathrm{~N}$ (shear force).

Inductive measurement sensors are less mature in development compared to capacitive and resistive systems. They are capable of highly accurate measurement (with resolution in the $\mathrm{mN}$ level [92]). Systems to date have not been optimal for plantar load measurement, either due to their bulky size or low measurement range. However, like capacitive sensors, their measurement range can be readily optimized by careful selection of the elastomer layer [93].

\section{Piezoelectric sensors}

A piezoelectric force sensor is a device based on the piezoelectric effect, acting to convert changes in force into an electrical charge. Piezoelectric force sensors are therefore typically associated with measuring dynamic phenomena but with appropriate signal processing can also be used to obtain quasi-static force measurements.

In 2017 Rajala et al. [42] designed a single-axis piezoelectric sensor for plantar pressure measurement. This sensor was made of a piezoelectric functional polymer polyvinylidenefluoride (PVDF) coated with copper electrodes on both sides. Characterisation showed it could effectively measure plantar pressure up to $486 \mathrm{kPa}(39 \mathrm{~N})$.

Triaxial piezoelectric force sensors have also been developed [94]. In 2003 Razian and Pepper [58] developed a triaxial transducer for an insole system utilizing a piezoelectric copolymer with the mixed composition of PVDF and trifluoroethylene. The sensor prototype was designed with a small size of $10 \mathrm{~mm} \times 10 \mathrm{~mm} \times 2.7 \mathrm{~mm}$. The sensor was sensitive to ambient temperature variations but obtained a wide measurement range of $700 \mathrm{~N}$ and $400 \mathrm{~N}$ (equivalent to $7000 \mathrm{kPa}$ and $400 \mathrm{kPa}$ ) for normal and shear force, respectively. In 2009 Kärki et al. [94] developed a triaxial piezoelectric sensor for plantar normal and shear stress measurements based on a commercial PVDF material. To distinguish force components, four separate sensing units were placed in a stack, as illustrated in Figure 7. It could measure the plantar pressure more than 200 $\mathrm{kPa}$ and shear stress of $60 \mathrm{kPa}$, however, the sensor size $(30 \mathrm{~mm}$ $\times 30 \mathrm{~mm} \times 2.4 \mathrm{~mm}$ ) renders it unsuited for high-spatialresolution plantar load measurements.

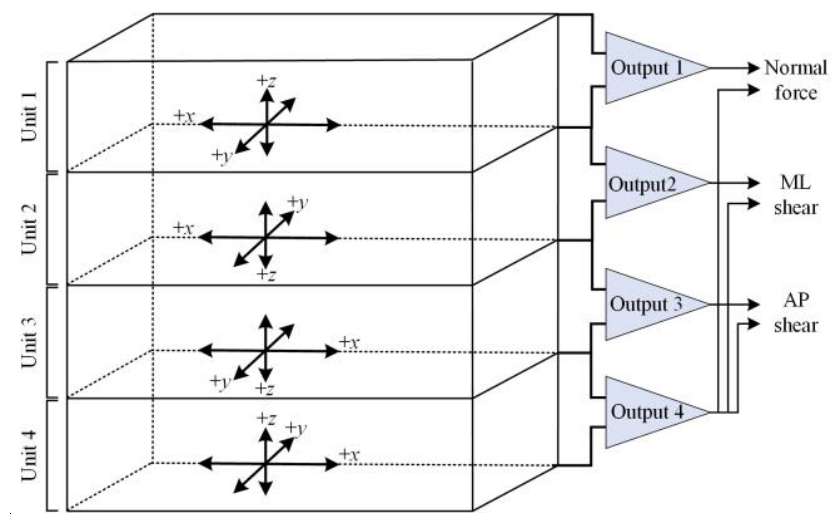


Figure 7. Principle of triaxial piezoelectric force sensor using four separate PVDF sensing units to measure normal, medial-lateral (ML) and anteriorposterior (AP) force components [94].

Piezoelectric sensors feature high sensitivity and can be fabricated using well understood techniques. However, it remains challenging to obtain multiaxial measurements from these systems, particularly within the size constraints required for plantar force monitoring applications [95].

\section{E. Fibre-optic sensing methods}

Fibre-optic sensing methods are popular for precise load measurement. One of the more prevalent methods is based on the fibre Bragg grating (FBG), which records force changes in the form of a reflection wavelength shift. FBGs are achieved by creating a periodic variation in the refractive index of the fibre core along the longitudinal axis of the optic fibre. As illustrated in Figure 8(a), FBGs back-reflect particular wavelengths (also called Bragg wavelengths) and transmit all others. The Bragg wavelength is determined by the grating period and the fibre core effective refractive index. Therefore, the physical parameters affecting the grating period or the effective refractive index, e.g. strain and temperature, can be detected by measuring the Bragg wavelength shift.

In 2016 Liang et al. [96] integrated six single-axis FBG pressure sensors into an insole for load measurement. Each FBG sensor had a size of $30.0 \mathrm{~mm} \times 20.0 \mathrm{~mm} \times 5.0 \mathrm{~mm}$ and was embedded in a silicone rubber to protect its function. Advancing this approach, in 2013 Zhang et al. [97] designed a biaxial FBG system, capable of simultaneously measuring normal and shear force. This used two optical fibres, each with one FBG, embedded in a soft PDMS matrix. One optical fibre was horizontally placed while the other one was tilted at an angle of $27^{\circ}$ away from the horizontal fibre. The measurement range achieved was $2.4 \mathrm{kPa}$ for pressure and $0.6 \mathrm{kPa}$ for the unidirectional shear stress. In 2018 Tavares et al. [98] proposed another biaxial FBG-based sensing cell for plantar normal and shear force measurement. This used two multiplexed FBGs in the same optical fibre, as shown in Figure 8(b). These two FBGs were incorporated in a small sensing cell with two cavities mechanically designed to regulate fibre deformation under load. A normal force applied to the top area of the sensing cell would compress the cell, inducing a positive Bragg wavelength shift while a shear force applied along the longitudinal axis would compress the cell, leading to a negative Bragg wavelength shift.

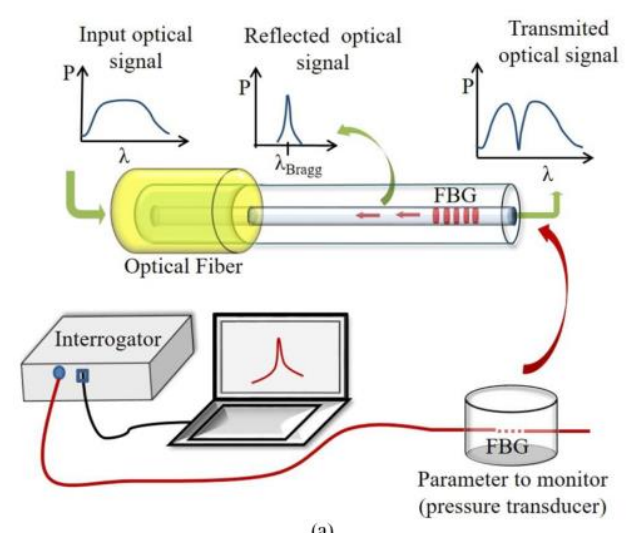

(a)

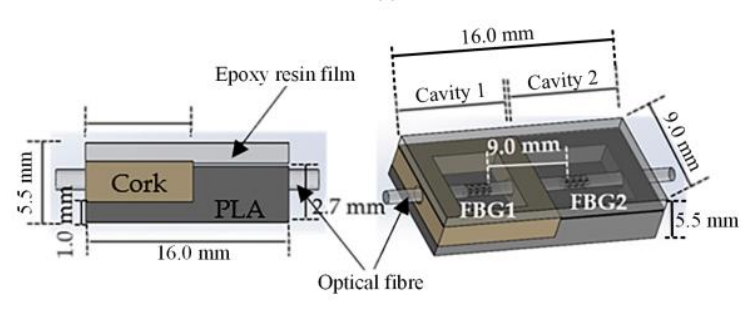

(b)

Figure 8. (a) FBG working principle [99]; (b) schematic illustration of the biaxial FBG sensing cells for normal and shear force measurements [98].

Another promising fibre-optic sensing technique is based on light intensity modulation. In 2005 Wang et al. [100] implemented a force sensor consisting of two fibre-optic meshes separated by gel/polymeric pads; each mesh comprised an array of optic fibres lying in perpendicular rows and columns, as illustrated in Figure 9. The measurements of the normal and shear force were based on the light intensity attenuation passing through the adjacent fibres due to the physical deformation; the normal force was detected by measuring the macro-bending induced light loss while shear force measurement was based on the variations in the relative position of the corresponding pressure points in the two mesh layers. The prototype consisted of two $2 \times 2$ matrix fibre meshes, forming eight pressure points where optic fibres intersected. Each pressure point was configured with a sensing area of $10 \mathrm{~mm} \times 10 \mathrm{~mm}$. The measurement resolution was 0.4 $\mathrm{N}$ for the normal force and $2.2 \mathrm{~N}$ for the shear force. To improve the resolution in the normal force measurement, in 2008 they modified the sensor design by using a larger array of fibres with an increased density in a $4 \times 4$ array of fibres spaced $2 \mathrm{~mm}$ apart [101]. The sensor prototype featured an improved resolution of $0.027 \mathrm{~N}$, but the measurement range was limited to $0.28 \mathrm{~N}$ (corresponding to $280 \mathrm{kPa}$ ). This sensing mechanism has been used by other researchers aiming to measure the plantar pressure and shear stress of people with diabetes [102]-[104]. Their focus was to optimize sensor performance, particularly sensitivity and measurement range for this application but to date there is limited technical evidence of the outcome. 


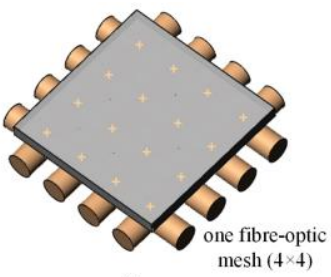

(a)
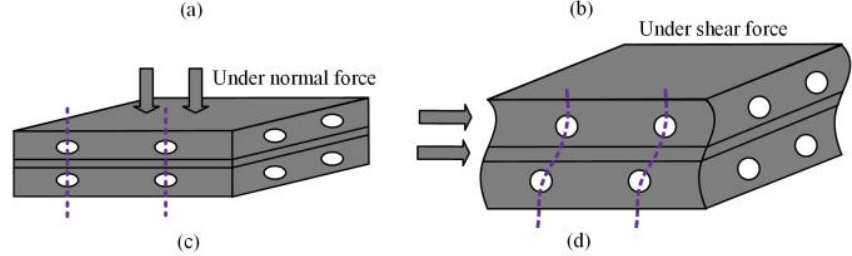

Figure 9. Fibre-optic normal and shear force sensing array [100]. (a) Basic structure of one fibre-optic mesh; (b) original configuration; (c) sensing array under normal force; (d) sensing array under shear force.

Optic fibre sensors have intrinsic virtues for wearable applications such as plantar load monitoring, including being lightweight, potentially high bandwidth and able to integrate sensing arrays within a single optic fibre. Nevertheless, they require non-trivial interrogation instruments to obtain measurements which can be bulky and power demanding. They are susceptible to changes in temperature [105], particularly FBG sensors [99], which could be problematic when located in close proximity to the foot's surface.

\section{F. Wireless sensing methods}

In addition to the more prevalent sensing techniques described above, wireless sensing methods have also been reported for the measurement of plantar load distributions.

In 2012, Mohammad and Huang [106] proposed an antennabased sensing method to measure plantar pressure. As shown in Figure 10(a), the sensor consisted of a reflector and a loop antenna, separated by a dielectric substrate. The reflector and the loop antenna could form an electromagnetic resonant cavity radiating at a distinct frequency. When a normal force was applied, the resonant frequency would decrease since the loop antenna was brought closer to the reflector plane. The same researchers then adapted this technique for single-axis shear force measurement (see Figure 10(b)) [107]. This exploited a change in resonant frequency as applied shear force alters the overlap between the antenna and the slot. In 2017 the team combined these elements to produce a single antenna sensor for simultaneous normal and shear force measurements [108] although the capability for shear force measurement was limited to a single axis. The wireless capability of these sensors is particularly suited to plantar measurement although it should be noted that they must be located in close proximity to a highfrequency $(5 \mathrm{GHz}+)$ communications unit which excites the remote antennas and processes the resultant signals. This may limit the range of this mode of sensor (e.g. to a clinical setting) and its ability to be used in an array, the subject of ongoing research.
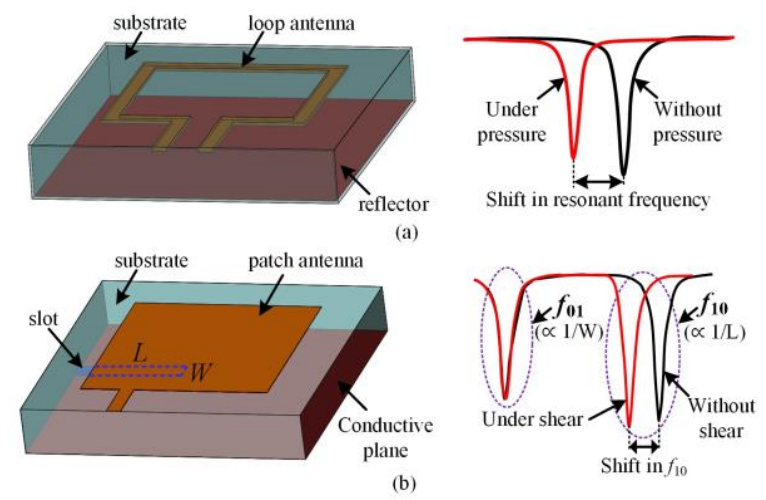

Figure 10. Principle of the antenna-based force sensors. (a) normal force sensor [106]; (b) shear force sensor [107].

\section{WEARABLE PLANTAR STRESS MEASUREMENT SYSTEMS}

By utilizing multiple force-sensing elements, both commercial and research groups have designed complete systems intended for the measurement of foot plantar load in real life. The developed systems can be mainly classified into static pressure-plates (which provide one or two stance phases 'snapshot' of the plantar surface) and wearable sensing footwear (which enables researchers to study the plantar surface over multiple stance phases in representative conditions/footwear and potentially allows users to move unconstrained through a typical environment). Plate-based systems have been instrumental in advancing our knowledge of plantar loading, particularly with regard to shear stress. The Cleveland Clinic Plate and related studies by Yavuz et al. [17], [54] have thus been key in informing the development of wearable plantar measurement systems and research continues, for instance in 2016 Keatsamarn and Pintavirooj [109] implemented a low-cost camera-based system to capture plantar pressure images. However, our focus in this review is the latter category of wearable footwear-based systems, an area which has received increasing attention for plantar stress measurements over recent years [46], [47], [72], [73], [110].

\section{A. Commercial footwear systems}

Several instrumented systems for measuring foot plantar load are commercially available. Table 2 summarizes the properties of key systems. Pedar ${ }^{\circledR}$ (Novel, Germany) [111] and F-Scan ${ }^{\mathrm{TM}}$ (Tekscan, Inc., South Boston, US) [112] systems are the most popular systems for research and clinical applications, although gait analysis in sport is arguably their target application.

The Pedar $^{\circledR}$ insole system integrates 85 - 99 capacitive sensors depending on the insole size, with a thickness of 1.9 $\mathrm{mm}$. It can be configured to measure pressure in the range of 15 - $600 \mathrm{kPa}$ or $30-1200 \mathrm{kPa}$ with a measurement resolution of $2.5 \mathrm{kPa}$ or $5 \mathrm{kPa}$ respectively. A data-recording module with a weight of $400 \mathrm{~g}$ is positioned on the user's waist, connected to the insole by wires running the length of the leg. The system can function in a mobile capacity with data storage or use builtin Bluetooth wireless technology. Putti et al. [113] assessed the repeatability of the Pedar ${ }^{\circledR}$ insole system by monitoring 53 healthy adults. They concluded that the Pedar ${ }^{\circledR}$ system was repeatable for plantar pressure measurement and can therefore be used in clinical assessment and diagnosis. Additionally, Bus 
et al. [114] and Waaijman [115] argued that the Pedar ${ }^{\circledR} \mathrm{X}$ system provides a useful tool to guide the modification of custom-made footwear for patients with diabetes. This would help maintain appropriate of the plantar surface according to the patients' recovery.

The F-Scan ${ }^{\mathrm{TM}}$ system provides a high-resolution alternative to Pedar $^{\circledR}$, employing 960 force-sensitive (resistive) sensors into a $0.15 \mathrm{~mm}$ thin insole to track plantar pressure patterns. However, the measurement range is reduced at $345-862 \mathrm{kPa}$. The manufacturer targets the F-Scan ${ }^{\mathrm{TM}}$ system for use in realworld applications including offloading the diabetic foot. In 2000 Randolph et al. [116] evaluated the measurement reliability of the F-Scan ${ }^{\mathrm{TM}}$ system while walking with ten healthy participants. The obtained pressure data showed the insole system was sufficiently reliable and could be used to monitor the patients' foot pressure distribution for DFU prevention. In 2014, using the F-Scan ${ }^{\mathrm{TM}}$ system, Amemiya et al. [117] studied the relationship between the gait features, the participants' characteristics including age, sex and body mass index, and the plantar pressure distribution in people with

diabetes; this research was aimed to investigate the factors associated with the development of DFU.

Other notable commercial systems include the medilogic WLAN insole (medilogic, Germany) [118], BioFoot ${ }^{\circledR}$ (Institute of Biomechanics of Valencia, Spain) [119], WalkinSense (Kinematix SA, Sheffield, UK) [120], W-INSHOE (Medicapteurs, France) [121], and MoveSole ${ }^{\circledR}$ (MoveSole Ltd, Finland) [122], which all bring similar plantar pressure monitoring capabilities. The medilogic WLAN system contains a maximum of 240 sensors, capable of measuring pressure up to $640 \mathrm{kPa}$ with a sampling frequency of $100 \mathrm{~Hz}$. Unlike the Pedar $^{\circledR}$ and F-Scan ${ }^{\mathrm{TM}}$ systems it only requires a small wireless transmission module to be attached at the lower leg allowing users to move within $100 \mathrm{~m}$ outside and $25 \mathrm{~m}$ inside buildings. Price et al. [123] compared the performance of three insole devices: medilogic (model: SohleFlex Sport), F-Scan ${ }^{\mathrm{TM}}$ (model: 3000E Sport), and Pedar ${ }^{\circledR}-\mathrm{X}$ to a range of loadings. They concluded that the Pedar ${ }^{\circledR} \mathrm{X}$ device performed well to all pressure loadings $(50-600 \mathrm{kPa})$ while the medilogic and $\mathrm{F}$ $\mathrm{Scan}^{\mathrm{TM}}$ systems provided effective measurements up to $200 \mathrm{kPa}$ to $300 \mathrm{kPa}$.

TABLE 2

COMMERCIAL PLANTAR PRESSURE MEASUREMENT FOOTWEAR SYSTEMS

\begin{tabular}{|c|c|c|c|c|c|}
\hline system & Sensing technology & $\begin{array}{l}\text { Number of sensors } \\
\text { for each foot }\end{array}$ & Pressure range & Sampling rate & Communication \\
\hline $\begin{array}{l}\text { medilogic } \\
\text { WLAN insole } \\
{[118]}\end{array}$ & Resistive sensors & $240(\max )$ & 6-640 kPa & $100-400 \mathrm{~Hz}$ & WLAN \\
\hline $\begin{array}{l}\text { WalkinSense } \\
{[120]}\end{array}$ & Resistive sensors & 8 & 1 & $100 \mathrm{~Hz}$ & Bluetooth \\
\hline $\begin{array}{l}\text { W-INSHOE } \\
{[121]}\end{array}$ & Resistive sensors & 9 & $9-694 \mathrm{kPa}$ & $100 \mathrm{~Hz}$ & Bluetooth \\
\hline $\begin{array}{l}\text { MoveSole } \AA \\
{[122]}\end{array}$ & Capacitive sensors & 7 & 1 & 1 & Bluetooth \\
\hline Moticon [124] & Capacitive sensors & 13 & $0-400 \mathrm{kPa}$ & $5,10,25,50,100 \mathrm{~Hz}$ & Wireless (ANT) \\
\hline $\begin{array}{l}\text { Orpyx } \log \mathrm{R}^{\mathrm{TM}} \\
(\mathrm{Gen} 2)[127]\end{array}$ & 1 & 37 & $0-517 \mathrm{kPa}$ & $256 \mathrm{~Hz}$ & Bluetooth \\
\hline FlexinFit [128] & Resistive sensors & 214 & $0-1000 \mathrm{kPa}$ & $25-50 \mathrm{~Hz}$ & Bluetooth \\
\hline Tactilus® [129] & Textile sensors & 16 & $7-330 \mathrm{kPa}$ & 1 & Bluetooth \\
\hline
\end{tabular}

The BioFoot ${ }^{\circledR}$ system is designed for gait analysis and footwear evaluation. Each insole has up to 64 measurement points; a higher sensor distribution density occurs at the areas of greatest interest (e.g. metatarsal heads). Martínez-Nova et al. [130] evaluated the BioFoot $^{\circledR}$ system for plantar pressure measurements with thirty healthy participants. They concluded that the system was reliable for use in real life settings and comparable to accepted commercial devices including F$\mathrm{Scan}^{\mathrm{TM}}$. The WalkinSense system is designed for in-shoe activity evaluation, including plantar pressure monitoring with gait speed and walking distance. It contains a triaxial accelerometer, a gyroscope, and eight piezoresistive pressure sensors. Castro et al. [131] used the system to track 40 healthy participants during walking in which it demonstrated a high accuracy for plantar pressure variables. While most systems use insoles with fixed sensor locations, the W-INSHOE system is equipped with nine resistive pressure sensors which can be positioned freely to any part of the foot or shoe, allowing users to adjust the sensor location easily. However, the sensor distribution needs to be carefully considered to obtain an accurate and repeatable measurement for plantar pressure distribution [132]. A more focused approach is adopted in the MoveSole ${ }^{\circledR}$ system [122], designed specifically to inform the recovery of diabetes-related foot disorders. Pressure data is acquired from seven sensors embedded into each insole and wirelessly transmitted to a mobile application in real time.

It is notable that all the commercially available systems are limited to plantar pressure measurement, providing no capacity 
for shear load monitoring. There is a variety of general purpose systems like Pedar® which are well suited for controlled environments but relatively few have targeted usage in real life environments or specific use for clinical assessment.

\section{B. Research-based footwear devices}

Despite the range of commercially available systems, academic researchers have also been developing their own wearable devices for plantar load measurement. This research is driven from factors including reducing cost, improving measurement capability or performance and focusing on particular applications. Systems aimed at the prevention and management of DFUs are summarized in Table 3. The majority of these systems only use a limited number of sensing elements to monitor select locations (as opposed to full coverage of the plantar surface) and these are denoted as 'Plantar regions of interest'. Unfortunately, many studies do not report complete information on sensor performance (measurement range in particular) but available data is included within 'Measurement capability'.

TABLE 3

SEVERAL RESEARCH-BASED FOOTWEAR SYSTEMS FOR MONITORING FOOT PLANTAR LOAD

\begin{tabular}{|c|c|c|c|c|c|c|c|c|c|}
\hline Year & System & $\begin{array}{l}\text { Shoes used } \\
\text { for testing }\end{array}$ & $\begin{array}{l}\text { Sensing } \\
\text { technology }\end{array}$ & $\begin{array}{l}\text { Number } \\
\text { of } \\
\text { sensors }\end{array}$ & $\begin{array}{l}\text { Spatial resolution/ } \\
\text { Sensor size }(\mathrm{mm})\end{array}$ & $\begin{array}{l}\text { Plantar regions of } \\
\text { interest }\end{array}$ & $\begin{array}{c}\text { Measurement } \\
\text { capability } \\
\text { (Pressure and/or } \\
\text { Shear Stress) } \\
\end{array}$ & $\begin{array}{l}\text { Sampli } \\
\text { ng rate }\end{array}$ & $\begin{array}{l}\text { Commun } \\
\text { ication }\end{array}$ \\
\hline 1983 & $\begin{array}{c}\text { Insole system } \\
{[24]}\end{array}$ & Dedicated & Resistive & $\begin{array}{c}6 \text { for } \\
\text { shear and } \\
6 \text { for } \\
\text { pressure }\end{array}$ & $\varnothing 16.0 \times 2.7$ & $\begin{array}{l}\text { Heel, hallux, } 2^{\text {nd }}- \\
5^{\text {th }} \text { MTHs }\end{array}$ & $\begin{array}{l}\text { Pressure and } \\
\text { unidirectional } \\
\text { shear }\end{array}$ & 1 & Wired \\
\hline 2000 & $\begin{array}{c}\text { Insole system } \\
\text { [77] }\end{array}$ & Dedicated & Resistive & 3 & $\varnothing 16.0 \times 3.8$ & $\begin{array}{c}\text { Heel, } 1^{\text {st }} \text { and } 3^{\text {rd }} \\
\text { MTHs or } 2^{\text {nd }} \text { and } 4^{\text {th }} \\
\text { MTHs }\end{array}$ & Shear & $100 \mathrm{~Hz}$ & Wired \\
\hline 2001 & $\begin{array}{c}\text { Insole system } \\
{[133]}\end{array}$ & Dedicated & Resistive & 4 & $25.5 \times 20.5$ & $\begin{array}{c}\text { Heel, } 1^{\text {st }}, 3^{\text {rd }} \text { and } 5^{\text {th }} \\
\text { MTHs }\end{array}$ & Pressure & $31 \mathrm{~Hz}$ & Wired \\
\hline 2003 & $\begin{array}{c}\text { Insole system } \\
{[58]}\end{array}$ & 1 & Piezoelectric & 4 & $13.0 \times 13.0 \times 2.7$ & $\begin{array}{c}\text { Heel, hallux, } 1^{\text {st }} \text { and } \\
5^{\text {th }} \text { MTHs }\end{array}$ & $\begin{array}{c}\text { Pressure and } \\
\text { shear }\end{array}$ & 1 & Wired \\
\hline 2010 & $\begin{array}{c}\text { Insole system } \\
{[110]}\end{array}$ & Dedicated & Resistive & 6 & 1 & Heel, $1^{\text {st }}-3^{\text {rd }}$ MTHs & $\begin{array}{l}\text { Pressure }(10 \mathrm{~Pa} \\
-800 \mathrm{kPa})\end{array}$ & $\begin{array}{c}100 \mathrm{~Hz} \\
(\max )\end{array}$ & Bluetooth \\
\hline 2011 & $\begin{array}{l}\text { Planipes } \\
\text { Insole [72] }\end{array}$ & $\begin{array}{l}\text { People's } \\
\text { own }\end{array}$ & $\begin{array}{c}\text { Resistive } \\
\text { (commercial) }\end{array}$ & 16 & 1 & $\begin{array}{l}\text { Heel, toes, forefoot, } \\
\text { midfoot }\end{array}$ & Pressure & $40 \mathrm{~Hz}$ & Bluetooth \\
\hline 2011 & $\begin{array}{l}\text { Insole system } \\
\text { [134] }\end{array}$ & $\begin{array}{l}\text { People's } \\
\text { own }\end{array}$ & $\begin{array}{c}\text { Resistive } \\
\text { (commercial) }\end{array}$ & 7 & $15.0 \times 10.0 \times 0.8$ & $\begin{array}{l}\text { Heel, hallux, } 1^{\text {st }} \\
\text { MTH, lateral and } \\
\text { centre midfoot, } \\
\text { lateral and centre } \\
\text { forefoot }\end{array}$ & $\begin{array}{l}\text { Pressure } \\
(25-250 \mathrm{kPa})\end{array}$ & $20 \mathrm{~Hz}$ & Wireless \\
\hline 2012 & $\begin{array}{l}\text { Insole system } \\
\text { [57] }\end{array}$ & Dedicated & $\begin{array}{c}\text { Resistive } \\
\text { (commercial) }\end{array}$ & 5 & $\varnothing 25.4$ & $\begin{array}{l}\text { Heel, hallux, } 1^{\text {st }}, 2^{\text {nd }} \text {, } \\
\text { and } 5^{\text {th }} \text { MTHs }\end{array}$ & Pressure & $250 \mathrm{~Hz}$ & Wired \\
\hline 2012 & $\begin{array}{l}\text { Insole system } \\
\text { [135] }\end{array}$ & $\begin{array}{l}\text { People's } \\
\text { own }\end{array}$ & Resistive & 48 & $10.0 \times 10.0$ & $\begin{array}{l}\text { Almost uniformly } \\
\text { distributed in the } \\
\text { insole }\end{array}$ & Pressure & $100 \mathrm{~Hz}$ & Bluetooth \\
\hline 2012 & $\begin{array}{l}\text { Shoe sole } \\
\text { system [136] }\end{array}$ & Dedicated & Capacitive & 4 & $20.0 \times 20.0$ & $\begin{array}{l}\text { Heel, hallux, } 1^{\text {st }} \text { and } \\
2^{\text {nd }} \text { MTHs }\end{array}$ & Pressure & 1 & $\begin{array}{l}\text { Wireless } \\
(\mathrm{XBee})\end{array}$ \\
\hline 2014 & $\begin{array}{l}\text { Insole system } \\
\text { [137] }\end{array}$ & $\begin{array}{l}\text { People's } \\
\text { own }\end{array}$ & $\begin{array}{c}\text { Resistive } \\
\text { (commercial) }\end{array}$ & 3 & 1 & $\begin{array}{l}\text { Heel, } 1^{\text {st }} \text { and } 5^{\text {th }} \\
\text { metatarsus }\end{array}$ & Pressure & $20 \mathrm{~Hz}$ & Wireless \\
\hline 2014 & $\begin{array}{l}\text { Sock-knitted } \\
\text { system [138] }\end{array}$ & 1 & Resistive & 8 & 1 & $\begin{array}{l}\text { Heel, hallux, MTHs, } \\
5^{\text {th }} \text { metatarsal base }\end{array}$ & Pressure & 1 & Bluetooth \\
\hline 2015 & $\begin{array}{l}\text { Insole system } \\
\text { [73] }\end{array}$ & Dedicated & $\begin{array}{c}\text { Resistive } \\
\text { (commercial) }\end{array}$ & 6 & $\varnothing 18.3$ & $\begin{array}{l}\text { Heel, Hallux, medial } \\
\text { and lateral forefoot, } \\
\text { medial and lateral } \\
\text { midfoot }\end{array}$ & Pressure & 1 & Bluetooth \\
\hline 2015 & $\begin{array}{l}\text { Insole system } \\
\text { [139] }\end{array}$ & 1 & Capacitive & 32 & 1 & $\begin{array}{l}\text { Almost uniformly } \\
\text { distributed in the } \\
\text { insole }\end{array}$ & Pressure & 1 & Bluetooth \\
\hline 2015 & $\begin{array}{l}\text { Insole system } \\
{[140]}\end{array}$ & 1 & $\begin{array}{l}\text { Capacitive or } \\
\text { resistive }\end{array}$ & 24 & 1 & Heel, forefoot & Pressure & $\begin{array}{l}50-75 \\
\mathrm{~Hz}\end{array}$ & $\begin{array}{l}\text { Flash } \\
\text { memory/ } \\
\text { Bluetooth }\end{array}$ \\
\hline 2016 & $\begin{array}{l}\text { Insole system } \\
\text { [43] }\end{array}$ & $\begin{array}{l}\text { People's } \\
\text { own }\end{array}$ & Resistive & 6 & $\varnothing 9.0$ & $\begin{array}{l}\text { Heel, hallux, } \\
\text { midfoot, lateral, } \\
\text { middle, and medial } \\
\text { forefoot }\end{array}$ & Pressure & $100 \mathrm{~Hz}$ & Wired \\
\hline 2016 & $\begin{array}{l}\text { Insole system } \\
\text { [141] }\end{array}$ & Dedicated & Piezoelectric & 3 & $\varnothing 18.0$ & $\begin{array}{l}\text { Heel, lateral and } \\
\text { medial MTHs }\end{array}$ & Pressure & 1 & Wired \\
\hline 2016 & $\begin{array}{l}\text { Foot-attached } \\
\text { system [142] }\end{array}$ & $\begin{array}{l}\text { People's } \\
\text { own }\end{array}$ & Piezoelectric & 4 & $\varnothing 14.3 \times 1.3$ & $1^{\text {st }}$ and $2^{\text {nd }}$ MTHs & $\begin{array}{l}\text { Pressure and } \\
\text { shear }\end{array}$ & $100 \mathrm{~Hz}$ & Bluetooth \\
\hline 2017 & $\begin{array}{l}\text { Insole system } \\
\text { [143] }\end{array}$ & Dedicated & $\begin{array}{c}\text { Resistive } \\
\text { (commercial) }\end{array}$ & 5 & 1 & $\begin{array}{l}\text { Heel, Hallux, } 1^{\text {st }} \text { and } \\
4^{\text {th }} \text { MTHs, lateral } \\
\text { arch }\end{array}$ & Pressure & $200 \mathrm{~Hz}$ & Bluetooth \\
\hline
\end{tabular}




\begin{tabular}{|c|c|c|c|c|c|c|c|c|c|}
\hline 2017 & $\begin{array}{l}\text { Sock-based } \\
\text { system [41] }\end{array}$ & $\begin{array}{l}\text { People's } \\
\text { own }\end{array}$ & Resistive & 4 & 1 & $\begin{array}{l}\text { Heel and MTHs }\left(1^{\text {st }} \text {, }\right. \\
\left.3^{\text {rd }}, 5^{\text {th }}\right)\end{array}$ & $\begin{array}{l}\text { Pressure (60- } \\
1000 \mathrm{kPa})\end{array}$ & 1 & RFID \\
\hline 2017 & $\begin{array}{l}\text { Insole system } \\
{[42]}\end{array}$ & 1 & Piezoelectric & 8 & $\varnothing 10.0$ & $\begin{array}{l}\text { Heel, hallux, } 1^{\text {st }}-5^{\text {th }} \\
\text { MTHs }\end{array}$ & Pressure & 1 & Wired \\
\hline 2017 & $\begin{array}{l}\text { Insole system } \\
\text { [144] }\end{array}$ & Dedicated & FBG & 6 & $\varnothing 10.0 \times 5.0$ & $\begin{array}{l}\text { Heel, hallux, } 1^{\text {st }} \text { and } \\
3^{\text {rd }} \text { MTHs, midfoot }\end{array}$ & Pressure & 1 & Wired \\
\hline 2018 & $\begin{array}{l}\text { Insole system } \\
\text { [98] }\end{array}$ & Dedicated & FBG & 5 & $16.0 \times 9.0 \times 5.5$ & $\begin{array}{l}\text { Heel, hallux, } \\
\text { midfoot, } 1^{\text {st }} \text { and } 3^{\text {rd }} \\
\text { MTHs }\end{array}$ & $\begin{array}{l}\text { Pressure and } \\
\text { unidirectional } \\
\text { shear }\end{array}$ & 1 & Wired \\
\hline
\end{tabular}

Note: 'Dedicated' in the $3^{\text {rd }}$ column refers to the case in which a specifically designed or specific shoe was used to test the insole system.

From Table 3, it can be seen that while most systems are based around an insole, some take a more direct approach with sensors attached either to the shoe outsole [136] a sock [41], [138] or directly to the foot [121], [142], [145], [146]. As shown in Figure 11(a), Mazumder et al. [136] placed four capacitive pressure sensors to the bottom side of the shoe. However this attachment method was found to be inconvenient for individuals donning and removing the system. Instead, Perrier et al. [138] developed a smart sock knitted with eight piezoresistive sensors to monitor the plantar pressure patterns, as shown in Figure 11(b). The piezoresistive fibres were used as a sensing material and silver-coated fibres were employed to transmit the signal. This resulted in reliable contact detection but the measurements were sensitive to sensor placement and thus the sock must be correctly and carefully worn. To overcome this problem, Lin and Seet [41] sewed two traces on the sock to guide the users; one trace moving across the central axis from the middle toe position was designed for checking misalignment in the horizontal direction, the other one around the ankle position for height. To avoid any slippage between the foot and the sensing elements, Amemiya et al. [142] attached four triaxial piezoelectric sensors directly onto the foot, as shown in Figure 11(c). They used this system to track plantar stress in 12 non-diabetic participants with callus at the $2^{\text {nd }}$ MTH. However, this approach is aimed at controlled environments and faces challenges in reliably applying sensors to sensitive areas of the foot without inducing skin damage.

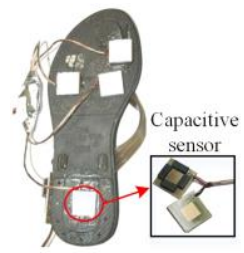

(a)

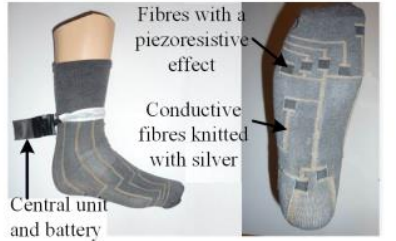

(b)

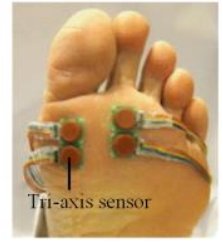

(c)
Figure 11. (a) Shoe outsole based plantar load measurement system [136]; (b) smart sock knitted with eight piezoresistive sensors [138]; (c) plantar triaxial sensors directly attached onto the foot [142].

Much like their commercial counterparts, the majority of wearable research systems come in the form of an instrumented insole. This brings advantages notably reliable and convenient positioning of sensors relative to the plantar surface, together with a stable structure within which to house them. Figure 12 shows several key insole-based wearable systems. Early work is shown in Figure 12(a) in which six commercial FSRs were used to capture the pressure at the heel, hallux, forefoot and midfoot [73]. To provide a uniformly distributed stress on the active sensing area, a rigid dome made of epoxy and metal was glued to each FSR. Similarly, the insole-based measurement system developed by Rajala et al. [141] initially contained three piezoelectric pressure sensors, later increased to monitor the heel, hallux, and five MTHs with eight sensors [42] (see Figure 12(b)). Conditioning and interface circuitry required a wired connection to an acquisition PC. Domingues et al. [99], [144] incorporated six FBG strain sensors into an insole, the sensors' location illustrated in Figure 12(e). To protect the sensing elements, the FBG sensors were embedded in an epoxy resin cylindrical structure $(\varnothing 10.0 \mathrm{~mm} \times 5 \mathrm{~mm})$. Again, sensor interface circuitry required a wired connection to a host PC.

Some researchers have considered improved coverage of the plantar surface. The smart insole designed by Mustufa et al. [139] used an array of 32 capacitive pressure sensors. As shown in Figure 12(c), all the sensors were placed on the top side of the insole and the pressure values were measured and processed by the conditioning circuitry fixed on the bottom side. Leemets et al. [140] designed the platform for a wireless pressure sensing insole with 24 sensing locations. As shown in Figure 12(d), the insole included five layers: bottom electrode, bottom silicon, flexible electronics, top electrode, and top silicon layers. However, the performance of the system equipped with sensing elements has yet to be presented.

Although the majority of wearable plantar load measurement systems are only sensitive to plantar pressure, expanding these capabilities has been an area of research interest. Mori et al. [147] integrated three commercially-available shear sensors with the F-Scan ${ }^{\mathrm{TM}}$ pressure sensing insole. Two uniaxial shear sensors $(35 \mathrm{~mm} \times 35 \mathrm{~mm} \times 1.2 \mathrm{~mm})$ were placed at the medial and the lateral MTHs, another biaxial shear sensor $(40 \mathrm{~mm} \times 40$ $\mathrm{mm} \times 3 \mathrm{~mm}$ ) fixed at the heel. The additional sensing elements added significant bulk, increasing the insole thickness to $7 \mathrm{~mm}$ (from that of the F-Scan ${ }^{\mathrm{TM}}$ system of $0.15 \mathrm{~mm}$ ) and providing a low spatial resolution for plantar shear stress. In 2018 Tavares et al. [98] used a novel biaxial FBG-based sensing cell (see Figure 8(b)) to develop an insole system for simultaneous measurement of plantar pressure and shear stress. As shown in Figure 12(f), the five FBG sensing cells were placed at the heel (P1), metatarsal (P2 and P4), toe (P3), and midfoot (P5). The insole system is currently only sensitive to shear stress along a single axis and expanding this to a triaxial system is the focus of ongoing work.

In general, the capabilities of these research grade wearable systems are inferior to commercial systems in aspects such as spatial resolution, measurement range and general robustness. However, they have been important in driving developments in this field, for instance in systems focused at particular clinical uses (like DFUs), exploring novel sensing technologies (which could help lower costs) and in particular exploring multiaxial measurement to enhance the capabilities of these systems and thus their potential clinical value. 


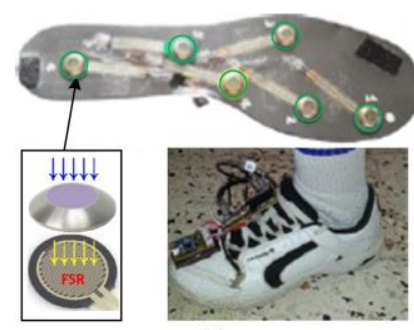

(a)

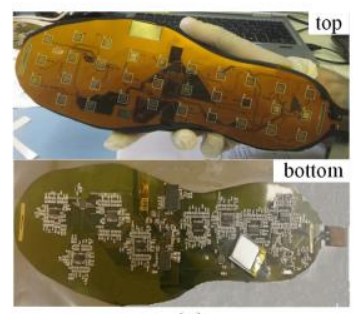

(c)

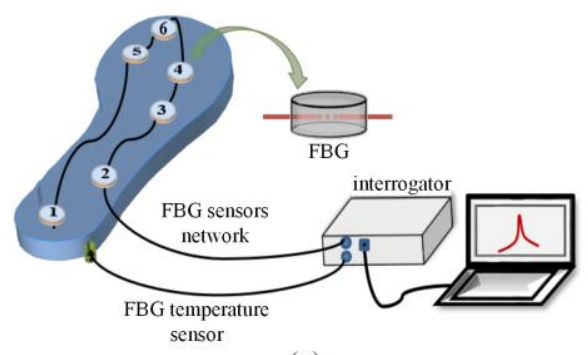

(e)

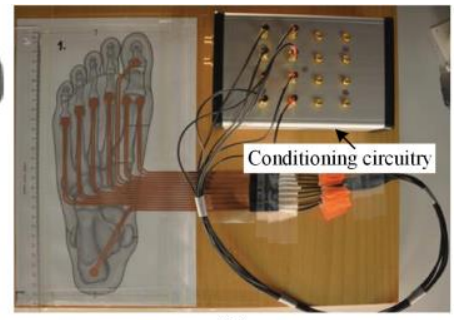

(b)



(d)

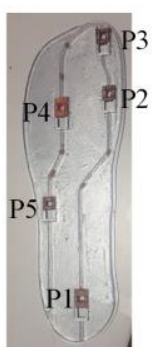

(f)
Figure 12. Insole-based footwear systems for plantar stress measurement. (a) Plantar pressure detection insole [73]; (b) The insole measurement system with eight piezoelectric sensing nodes [42]; (c) sensor interface side and electronic component side of an instrumented insole [139]; (d) all layers of an insole-based sensory system [140]; (e) the insole embedded with the FBG pressure sensor network [99]; (f) an instrumented insole for the plantar pressure and shear stress monitoring, incorporating five biaxial FBG sensing cells [98].

\section{DISCUSSION}

Plantar load distributions have been extensively studied to inform our understanding of the formation, assessment and prevention of DFUs. The evolution of this research field is closely coupled with the advancement of plantar load measurement systems and the capability of underlying sensing technologies, thus advances in our understanding have driven demand for improved sensing technology. In this section, we reflect on the current state of DFU measurement technology, highlight emergent trends and discuss future research challenges.

\section{A. Current state of wearable load measurement for DFU}

In section II we presented evidence-based requirements for wearable plantar load measurement systems appropriate for DFU assessment. These form a natural reference against which to compare the capabilities of current measurement technology.

A key aspect in load monitoring is the number of axes which can be measured. There is growing recognition that plantar shear stress is likely to be a strong predicator of DFU development and deterioration, thus demanding multiaxial load measurement systems. It is notable that current commercial systems (e.g. the Pedar® and F-Scan ${ }^{\mathrm{TM}}$ systems) are limited to single-axis plantar pressure measurement. However, multiaxial load measurement systems are beginning to emerge in research, exploiting advances in fundamental load sensing technology. It is difficult to rigorously compare the performance of different sensing technologies with the limited information available in literature (see Table 2). Aspects of sensitivity, bandwidth, hysteresis and sensitivity are often not reported. Nevertheless, themes can be drawn from the capabilities of systems which have been developed. Capacitive sensors have proved particularly effective in realizing complete measurement systems (see for example Mustufa et al. [139]). Fibre-optic systems also show promise, although it remains unclear if this technology, which demands complex interface circuitry, will scale well to high numbers of sensors. Sensors using inductive or electromagnetic coils may provide a compelling alternative to capacitive sensors (in particular offering good robustness to environmental conditions), although their use has currently been limited to demonstrating feasibility in a single sensor 'node'.

The spatial coverage and resolution of measurement systems has significant implications for their use. Commercial systems typically employ small, thin-film single-axis pressure sensing elements. This approach permits a high density of sensors, distributed across the plantar surface, in a low-profile sensing insole (see for example F-Scan ${ }^{\mathrm{TM}}$ ). Conversely, where research based systems have sought to integrate multiaxial sensing, each individual node is significantly larger in size than their singleaxis counterpart. This tends to result in a thicker insole with a limited number of measurement nodes located at strategic locations on the plantar surface. This is a prudent way to evaluate system performance at a developmental stage (thus avoiding the complexity of interfacing high numbers of sensing elements). However, without careful consideration this approach risks missing important plantar load information which occurs outside accepted plantar loading 'hot spots'. For example, observing shifting load patterns prior to DFU formation or monitoring the outcome of pressure offloading strategies.

It is notable that the majority of the wearable systems presented in this review are intended for use in controlled environments, either research laboratory or a clinical setting. Accordingly, while the use of wireless technology is prevalent, and permits relatively unencumbered movement, it also requires a $\mathrm{PC}$-based interface in the immediate region for data logging and control. Of the few systems which seek to support sensing in real-life environments, there remains significant work to develop systems which are user friendly, comfortable and robust (in system and sensing terms) to long term use in variable environments.

\section{B. Development Trends of Sensing Technologies for Measuring DFUs}

Advances in electronic load-sensing technology have enabled the development of specific systems for plantar load measurement. To date, the field has been dominated by generalpurpose commercial systems designed for research purposes. These have been instrumental in transforming our understanding of DFU, in particular allowing investigation into the relationship between plantar stress distribution and DFU disease progression. Biomedical research has made extensive 
use of the Pedar® insole and F-Scan ${ }^{\mathrm{TM}}$ systems. However, these systems have major limitations from a clinical perspective including limited measurement functionality (lacking multiaxial load measurement), high-cost, and lengthy setup time. This has precluded them from use in routine clinical practice, despite their potential virtues to inform assessment and treatment. However, emerging research literature highlights a move to develop measurements systems specifically for plantar load measurement in DFU prevention. Given the huge healthcare costs associated with DFU treatment there is reason to expect that market demands will help drive innovation in this area and aid translation of research into commercially available systems.

In this context, another significant trend is the development of multimodal measurement systems. Tissue health at the plantar surface has been linked to changes in temperature and/or $\mathrm{pH}$ [148], where a reduction in foot temperature and $\mathrm{pH}$ indicates healing processes [149]. $\mathrm{pH}$ conditions within wounds can also indicate the presence of infection and thereby could be measured to enhance the management of DFU infections [150]. Similarly, studies show that elevated plantar stress might induce a progressive rise in the foot temperature and so accelerate tissue breakdown and foot ulceration [149], [151]. Foot temperature has also been explored as a low fidelity surrogate for plantar shear stress [25], [133], [152]. Therefore, a multimodal sensing system which can combine $\mathrm{pH}$ and/or temperature with multiaxial load has the potential to provide enhanced assessment capabilities which directly relate to clinical practice.

\section{Future challenges in DFU measurements}

Despite many advances made in DFU load sensing, there remain a number of key challenges that need to be addressed before clinical use and patient benefit is more widespread.

From a technical perspective, one of the major challenges is achieving multiaxial load measurement in a form which meets or surpasses the capabilities of current commercial single-axis systems like Pedar®. This necessitates sensor elements which are accurate and repeatable, integrated a system with a lowprofile form factor, 'wearable' physical characteristics (e.g. the ability to flex and conform to the plantar surface) and crucially overall system robustness. Addressing these challenges will require exploration of fundamental sensor science (to miniaturize sensing elements and improve performance) with fabrication methods (to reliably and accurately produce sensor arrays) and applied biomedical research to evaluate and optimize the resultant systems.

It is important to recognize that these technical developments must be accompanied by consideration of the context in which they are used. Adoption of new, potentially disruptive, technology into healthcare pathways is challenging and must be supported by inclusive design methods and compelling clinical evidence of its clinical efficacy and effectiveness. Hence it is critical that healthcare professionals and people with DFUs are consulted to inform system designs are appropriate. Furthermore, aspects of health economics are interlinked with system design and its intended use case. For instance, if a DFU load monitoring system has to be reusable and cost effective, this places demands on the use of designs and materials appropriate for cleaning and sterilization between users.
Accordingly, it is crucial that researchers in this field adopt a multidisciplinary approach to system development and evaluation. By doing so, it is evident that there is the potential to bring real clinical benefits to people with diabetes through the use of wearable plantar load sensing for DFU prevention.

\section{CONCLUSION}

This paper reviews sensing techniques and wearable footwear-based systems for measuring plantar load distribution of people with diabetes. The measurement requirements for DFU load monitoring systems are closely linked to clinical understanding which has evolved, highlighting a need for multiaxial measurements of pressure and shear stresses at the plantar surface.

Current sensing technologies are based on different operating principles and have been integrated into insoles, textile socks or directly on the foot for continuous stress measurements. Most prevalent are insole based systems of which there are a wide variety of successful commercial systems. However, these lack multiaxial measurement and are often prohibitively expensive for routine clinical use. In comparison, research based systems are less-well developed, notably in spatial resolution and coverage, but have pioneered multiaxial plantar load measurement using a range of different sensing modalities.

It is evident that further development is required to transform and translate plantar load sensing technology from a general purpose tool into a clinically useful tool for DFU assessment. Challenges encompass technological factors, practical aspects of real-world use and commercial considerations. By addressing these it is clear that wearable load sensing technology has the potential to bring real benefits in the prevention and treatment of DFUs.

\section{ACKNOWLEDGEMENT}

The research is supported by the National Institute for Health Research (NIHR) infrastructure at Leeds. The views expressed are those of the author(s) and not necessarily those of the NHS, the NIHR or the Department of Health and Social Care.

The authors would like to thank the NIHR MedTech and In Vitro diagnostics Co-operatives (MICs).

\section{REFERENCES}

[1] International Diabetes Federation, Eighth edition. 2017.

[2] C. A. Abbott et al., "The North-West Diabetes Foot Care Study: incidence of, and risk factors for, new diabetic foot ulceration in a community-based patient cohort," Diabet Med, vol. 19, pp. 377384, 2002.

[3] K. Al-Rubeaan et al., "Diabetic foot complications and their risk factors from a large retrospective cohort study," PLoS One, vol. 10, no. 5, pp. 1-17, 2015.

[4] I. S. Muller, W. J. C. de Grauw, W. H. E. M. van Gerwen, M. L. Bartelink, H. J. M. van den Hoogen, and G. E. H. M. Rutten, "Foot Ulceration and Lower Limb Amputation in Type 2 Diabetic Patients in Dutch Primary Health Care," Diabetes Care, vol. 25, no. 3, pp. 570-574, 2002.

[5] L. Yazdanpanah et al., "Incidence and Risk Factors of Diabetic Foot Ulcer: A Population-Based Diabetic Foot Cohort (ADFC Study) Two-Year Follow-Up Study," Int. J. Endocrinol., vol. 2018, pp. 19, Mar. 2018. 
[6] L. Hurley et al., "A prospective study of risk factors for foot ulceration: The West of Ireland Diabetes Foot Study," QJM, vol. 106, no. 12, pp. 1103-1110, Dec. 2013.

[7] S. D. Ramsey et al., "Incidence, outcomes, and cost of foot ulcers in patients with diabetes.," Diabetes Care, vol. 22, no. 3, pp. 382-7, Mar. 1999.

[8] G. P. Leese et al., "Stratification of foot ulcer risk in patients with diabetes: a population-based study," Int. J. Clin. Pract., vol. 60, no. 5, pp. 541-545, May 2006.

[9] H. Brem and M. Tomic-Canic, "Cellular and molecular basis of wound healing in diabetes," J Clin Invest, vol. 117, no. 5, pp. 1219 1222, 2007.

[10] G. Hoogeveen, RC. Dorresteijn, JAN. Kriegsman, DMW. Valk, "Complex interventions for preventing diabetic foot ulceration ( Review )," Cochrane Databases Syst. Rev., no. 8, 2015.

[11] D. G. Armstrong, A. J. M. Boulton, and S. A. Bus, "Diabetic Foot Ulcers and Their Recurrence," N. Engl. J. Med., vol. 376, no. 24, pp. 2367-2375, 2017.

[12] L. Prompers et al., "High prevalence of ischaemia, infection and serious comorbidity in patients with diabetic foot disease in Europe. Baseline results from the Eurodiale study," Diabetologia, vol. 50, no. 1, pp. 18-25, 2007.

[13] J. W. Walsh, O. J. Hoffstad, M. O. Sullivan, and D. J. Margolis, "Association of diabetic foot ulcer and death in a population-based cohort from the United Kingdom," Diabet. Med., vol. 33, no. 11, pp. 1493-1498, 2016.

[14] M. Kerr, "the Diabetic Foot Care in England : an Economic Study," Insight Heal. Econ. Diabetes UK, no. January, pp. 1-52, 2017.

[15] C. W. Care, "Prevention and management of diabetic foot ulcers," 2015.

[16] L. A. Lavery, D. G. Armstrong, R. P. Wunderlich, J. Tredwell, and A. J. M. Boulton, "Predictive value of foot pressure assessment as part of a population-based diabetes disease management program.," Diabetes Care, vol. 26, no. 4, pp. 1069-73, Apr. 2003.

[17] M. Yavuz, "Plantar shear stress distributions in diabetic patients with and without neuropathy," Clin. Biomech., vol. 29, no. 2, pp. 223-229, 2014.

[18] A. Veves, H. J. Murray, M. J. Young, and A. J. Boulton, “The risk of foot ulceration in diabetic patients with high foot pressure: a prospective study.," Diabetologia, vol. 35, no. 7, pp. 660-3, Jul. 1992.

[19] D. G. Armstrong, L. A. Lavery, B. P. Nixon, and A. J. M. Boulton, "It's Not What You Put On, but What You Take Off: Techniques for Debriding and Off-Loading the Diabetic Foot Wound," Clin. Infect. Dis., vol. 39, no. Supplement_2, pp. S92-S99, 2004.

[20] M. Yavuz, A. Erdemir, G. Botek, G. B. Hirschman, L. Bardsley, and B. L. Davis, "Peak Plantar Pressure and Shear Locations," Diabetes Care, vol. 30, no. 10, pp. 2643-2645, 2007.

[21] M. Yavuz, "Review of plantar shear and its relevance to diabetic ulceration," no. December, 2013.

[22] M. Yavuz, H. Master, A. Garrett, L. A. Lavery, and L. S. Adams, "Peak Plantar Shear and Pressure and Foot Ulcer Locations: A Call to Revisit Ulceration Pathomechanics.," Diabetes Care, vol. 38, no. 11, pp. e184-5, Nov. 2015.

[23] M. Hamatani et al., "Factors Associated with Callus in Patients with Diabetes, Focused on Plantar Shear Stress during Gait," J. Diabetes Sci. Technol., vol. 10, no. 6, pp. 1353-1359, 2016.

[24] J. P. Pollard and L. P. Le Quesne, "Method of healing diabetic forefoot ulcers.," Br. Med. J. (Clin. Res. Ed)., vol. 286, no. 6363, pp. 436-437, 1983.

[25] S. A. Bus, "Innovations in plantar pressure and foot temperature measurements in diabetes," Diabetes. Metab. Res. Rev., vol. 32, no. 30, pp. 13-23, 2016.

[26] A. N. Sidawy, Diabetic foot: lower extremity arterial disease and limb salvage, 1st ed. Lippincott Williams \& Wilkins, 2006.

[27] NICE, "Diabetic foot problems : prevention and management," $J$. Fam. Community Med., vol. 20, no. 1, p. 1, 2015.

[28] S. A. Bus et al., "IWGDF Guideline on the prevention of foot ulcers in persons with diabetes," Int. Work. Gr. Diabet. foot, 2019.

[29] L. A. Lavery, J. Lafontaine, K. R. Higgins, D. R. Lanctot, and G. Constantinides, "Shear-reducing insoles to prevent foot ulceration in high-risk diabetic patients," Adv. Ski. Wound Care, vol. 25, no. 11, pp. 519-524, 2012.

[30] Si. A. Bus et al., "Effect of custom-made footwear on foot ulcer recurrence in diabetes: A multicenter randomized controlled trial,"
Diabetes Care, vol. 36, no. 12, pp. 4109-4116, 2013.

[31] L. Yazdanpanah, "Literature review on the management of diabetic foot ulcer," World J. Diabetes, vol. 6, no. 1, p. 37, 2015.

[32] G. Jarl and R. Tranberg, "An innovative sealed shoe to off-load and heal diabetic forefoot ulcers-a feasibility study," Diabet. Foot Ankle, vol. 8, no. 1, pp. 1-4, 2017.

[33] R. T. Crews, A. L. King, S. V. Yalla, and N. J. Rosenblatt, "Recent advances and future opportunities to address challenges in offloading diabetic feet: A mini-review," Gerontology, vol. 64, no. 4, pp. 309-317, 2018.

[34] A. J. M. Boulton, "Pressure and the diabetic foot: Clinical science and offloading techniques," Am. J. Surg., vol. 187, no. 5 SUPPL. 1, pp. S17-S24, 2004.

[35] D. G. Armstrong, H. C. Nguyen, L. A. Lavery, C. H. M. Van Schie, A. J. M. Boulton, and L. B. Harkless, "Off-loading the diabetic foot wound: A randomized clinical trial," Diabetes Care, vol. 24, no. 6, pp. 1019-1022, 2001.

[36] D. J. Gutekunst, M. K. Hastings, K. L. Bohnert, M. J. Strube, and D. R. Sinacore, "Removable cast walker boots yield greater forefoot off-loading than total contact casts," Clin. Biomech., vol. 26, no. 6, pp. 649-654, 2011.

[37] D. Erdenechimeg, D. Enkhzul, O. Munkhtamir, and B. Enkhbat, "Wireless monitoring method for diabetic foot temperature," pp. 39-43, 2017.

[38] T. Hughes-Riley, P. Lugoda, T. Dias, C. L. Trabi, and R. H. Morris, "A study of thermistor performance within a textile structure," Sensors (Switzerland), vol. 17, no. 8, 2017.

[39] P. Salvo et al., "Temperature-and $\mathrm{pH}$-sensitive wearable materials for monitoring foot ulcers," Int. J. Nanomedicine, vol. 12, pp. 949954, 2017.

[40] J. de J. Sandoval-Palomares, J. Yáñez-Mendiola, A. GómezEspinosa, and J. M. López-Vela, "Portable system for monitoring the microclimate in the footwear-foot interface," Sensors (Switzerland), vol. 16, no. 7, 2016.

[41] X. Lin and B. C. Seet, "Battery-Free Smart Sock for Abnormal Relative Plantar Pressure Monitoring," IEEE Trans. Biomed. Circuits Syst., vol. 11, no. 2, pp. 464-473, 2017.

[42] S. Rajala, R. Mattila, I. Kaartinen, and J. Lekkala, "Designing, Manufacturing and Testing of a Piezoelectric Polymer Film In-Sole Sensor for Plantar Pressure Distribution Measurements," IEEE Sens. J., vol. 17, no. 20, pp. 6798-6805, Oct. 2017.

[43] C. Gerlach et al., "Printed MWCNT-PDMS-Composite Pressure Sensor System for Plantar Pressure Monitoring in Ulcer Prevention," vol. 15, no. July 2015, pp. 3647-3656, 2016.

[44] C. Chi, X. Sun, N. Xue, T. Li, and C. Liu, "Recent progress in technologies for tactile sensors," Sensors (Switzerland), vol. 18, no. 4, 2018.

[45] M. I. Tiwana, S. J. Redmond, and N. H. Lovell, "A review of tactile sensing technologies with applications in biomedical engineering," Sensors Actuators A. Phys., vol. 179, pp. 17-31, 2012.

[46] J. A. Ramirez-Bautista, J. A. Huerta-Ruelas, S. L. ChaparroCárdenas, and A. Hernández-Zavala, "A Review in Detection and Monitoring Gait Disorders Using In-Shoe Plantar Measurement Systems," IEEE Rev. Biomed. Eng., vol. 10, pp. 299-309, 2017.

[47] J. A. Ramirez-Bautista, A. Hernández-Zavala, S. L. ChaparroCárdenas, and J. A. Huerta-Ruelas, "Review on plantar data analysis for disease diagnosis," Biocybern. Biomed. Eng., vol. 38, no. 2, pp. 342-361, 2018.

[48] J. DeBerardinis, M. Trabia, and J. S. Dufek, "Review of Foot Plantar Pressure-Focus on the Development of Foot Ulcerations," Open Access J. Sci. Technol., vol. 3, 2016.

[49] S. Rajala and J. Lekkala, "Plantar shear stress measurements - A review," Clin. Biomech., vol. 29, no. 5, pp. 475-483, 2014.

[50] S. Urry, "Plantar pressure-measurement sensors," Meas. Sci. Technol., vol. 10, no. 1, 1999.

[51] A. H. Abdul Razak, A. Zayegh, R. K. Begg, and Y. Wahab, "Foot plantar pressure measurement system: A review," Sensors (Switzerland), vol. 12, no. 7, pp. 9884-9912, 2012.

[52] S. S. Zulkifli and W. P. Loh, "A state-of-the-art review of foot pressure," Foot Ankle Surg., Dec. 2018.

[53] M. Lord and R. Hosein, "A study of in-shoe plantar shear in patients with diabetic neuropathy," Clin. Biomech., vol. 15, no. 4, pp. 278283, May 2000.

[54] M. Yavuz, G. Botek, and B. L. Davis, "Plantar shear stress distributions: Comparing actual and predicted frictional forces at the 
foot-ground interface," J. Biomech., vol. 40, no. 13, pp. 3045-3049, Jan. 2007.

[55] M. Yavuz et al., "Plantar shear stress in individuals with a history of diabetic foot ulcer: An emerging predictive marker for foot ulceration," Diabetes Care, vol. 40, no. 2, pp. e14-e15, 2017.

[56] K. M. Pickwell, V. D. Siersma, M. Kars, P. E. Holstein, and N. C. Schaper, "Diabetic foot disease: impact of ulcer location on ulcer healing," Diabetes. Metab. Res. Rev., vol. 29, no. 5, pp. 377-383, Jul. 2013.

[57] S. Ostadabbas, A. Saeed, M. Nourani, and M. Pompeo, "Sensor architectural tradeoff for diabetic foot ulcer monitoring," Proc. Annu. Int. Conf. IEEE Eng. Med. Biol. Soc. EMBS, pp. 6687-6690, 2012.

[58] M. A. Razian and M. G. Pepper, "Design, development, and characteristics of an in-shoe triaxial pressure measurement transducer utilizing a single element of piezoelectric copolymer film," IEEE Trans. Neural Syst. Rehabil. Eng., vol. 11, no. 3, pp. 288-293, 2003.

[59] B. L. Davis, R. M. Cothren, P. Quesada, S. B. Hanson, and J. E. Perry, "Frequency content of normal and diabetic plantar pressure profiles: implications for the selection of transducer sizes.," $J$. Biomech., vol. 29, no. 7, pp. 979-83, Jul. 1996.

[60] V. Berki and B. L. Davis, "Spatial frequency content of plantar pressure and shear profiles for diabetic and non-diabetic subjects," J. Biomech., vol. 49, no. 15, pp. 3746-3748, 2016.

[61] Y.-L. Zheng et al., "Unobtrusive Sensing and Wearable Devices for Health Informatics," IEEE Trans. Biomed. Eng., vol. 61, no. 5, pp. 1538-1554, May 2014.

[62] L. Piwek, D. A. Ellis, S. Andrews, and A. Joinson, "The Rise of Consumer Health Wearables: Promises and Barriers," PLOS Med., vol. 13, no. 2, p. e1001953, Feb. 2016.

[63] Y. Wang, T. Hua, B. Zhu, Q. Li, W. Yi, and X. Tao, "Novel fabric pressure sensors: Design, fabrication, and characterization," Smart Mater. Struct., vol. 20, no. 6, 2011.

[64] L. Shu et al., "Monitoring diabetic patients by novel intelligent footwear system," ICCH 2012 Proc. - Int. Conf. Comput. Healthc., pp. 91-94, 2012.

[65] X. Lin and B.-C. Seet, "A Linear Wide-Range Textile Pressure Sensor Integrally Embedded in Regular Fabric,” IEEE Sens. J., vol. 15 , no. 10 , pp. 5384-5385, Oct. 2015.

[66] C. Gerlach, J. Lange, and O. Kanoun, "Carbon nanotube composite for application in gait analysis," Int. Multi-Conference Syst. Sygnals Devices, pp. 1-4, 2012.

[67] "FlexiForce Load/Force Sensors and Systems | Tekscan." [Online]. Available: https://www.tekscan.com/flexiforce-load-force-sensorsand-

systems?utm_source=google\&utm_medium $=$ cpc\&utm_term $=$ force + sensors\&utm_content=eta3\&utm_campaign=flexiforce. [Accessed: 03-Sep-2018].

[68] F. Zabihollahy, B. M. Trindade, Y. Ono, and E. D. Lemaire, "Continuous monitoring of mechanical properties of plantar soft tissue for diabetic patients using wearable ultrasonic and force sensors," 2016 IEEE EMBS Int. Student Conf. Expand. Boundaries Biomed. Eng. Heal. ISC 2016 - Proc., 2016.

[69] T. Bernard, C. D. Elia, R. Kabadi, and N. Wong, "An Early Detection System for Foot Ulceration in Diabetic Patients," Bioeng. Conf. 2009 IEEE 35th Annu. Northeast, pp. 1-2, 2009.

[70] Z. Zhang and S. Poslad, "Improved use of foot force sensors and mobile phone GPS for mobility activity recognition," IEEE Sens. J., vol. 14, no. 12, pp. 4340-4347, 2014.

[71] "Interlink Electronics." [Online]. Available: https://www.interlinkelectronics.com/. [Accessed: 03-Sep-2018].

[72] S. Pfaffen, P. Sommer, C. Stocker, R. Wattenhofer, and S. Welten, "Planipes: mobile foot pressure analysis," Proc. First ACM Work. Mob. Syst. Appl. Serv. Healthc., p. 2, 2011.

[73] A. S. Benbakhti, S. Boukhenous, C. Zizoua, and M. Attari, "An instrumented shoe for ambulatory prevention of diabetic foot ulceration," Proc. 2014 4th Int. Conf. Wirel. Mob. Commun. Healthc. - "Transforming Healthc. Through Innov. Mob. Wirel. Technol. MOBIHEALTH 2014, no. October, pp. 43-46, 2015.

[74] J. W. Tappin, J. P. Pollard, and E. A. Beckett, "Method of measuring shearing forces on the side of the foot," Clin. Phys. Physiol. Meas, vol. 1. pp. 83-85, 1980.

"Forces under the foot.".

[76] M. Lord, R. Hosein, and R. B. Williams, "Method for in-shoe shear stress measurement," Journal of Biomedical Engineering, vol. 14, no. 3. pp. 181-186, 1992.

[77] R. Hosein and M. Lord, "A study of in-shoe plantar shear in normals," Clin. Biomech., vol. 15, no. 1, pp. 46-53, 2000.

[78] D. Giovanelli and E. Farella, "Force Sensing Resistor and Evaluation of Technology for Wearable Body Pressure Sensing," $J$. Sensors, vol. 2016, pp. 1-13, Feb. 2016.

[79] Z. Del Prete, L. Monteleone, and R. Steindler, "A novel pressure array sensor based on contact resistance variation: Metrological properties ARTICLES YOU MAY BE INTERESTED IN A novel pressure array sensor based on contact resistance variation: Metrological properties," Rev. Sci. Instrum., vol. 72, p. 1548, 2001.

[80] K. F. Lei, K. F. Lee, and M. Y. Lee, "Development of a flexible PDMS capacitive pressure sensor for plantar pressure measurement," Microelectron. Eng., vol. 99, pp. 1-5, 2012.

[81] L. Motha, J. Kim, and W. S. Kim, "Instrumented rubber insole for plantar pressure sensing," Org. Electron. physics, Mater. Appl., vol. 23, pp. 82-86, 2015.

[82] J. A. Dobrzynska and M. A. M. Gijs, "Polymer-based flexible capacitive sensor for three-axial force measurements," $J$. Micromechanics Microengineering, vol. 23, no. 1, 2013.

[83] G. Liang, Y. Wang, D. Mei, K. Xi, and Z. Chen, "Flexible Capacitive Tactile Sensor Array with Truncated Pyramids as Dielectric Layer for Three-Axis Force Measurement," $J$. Microelectromechanical Syst., vol. 24, no. 5, pp. 1510-1519, 2015.

[84] H.-K. Lee, J. Chung, S.-I. Chang, and E. Yoon, "Normal and Shear Force Measurement Using a Flexible Polymer Tactile Sensor With Embedded Multiple Capacitors," Microelectromechanical Syst. J., vol. 17, no. 4, pp. 934-942, 2008.

[85] A. Charalambides and S. Bergbreiter, "A novel all-elastomer MEMS tactile sensor for high dynamic range shear and normal force sensing," J. Micromechanics Microengineering, vol. 25, no. 9, 2015.

[86] L. Martinelli, C. Hurschler, and D. Rosenbaum, "Comparison of Capacitive versus Resistive Joint Contact Stress Sensors," Clin. Orthop. Relat. Res., vol. 447, pp. 214-220, Jun. 2006.

[87] M. J. Warren-Forward, R. M. Goodall, and D. J. Pratt, "Threedimensional displacement and force transducer," Sci. Meas. Technol. IEE Proc. A, vol. 139, no. 1, pp. 21-29, 1992.

[88] S. Wattanasarn, K. Noda, K. Matsumoto, and I. Shimoyama, "3D flexible tactile sensor using electromagnetic induction coils," 2012 IEEE 25th Int. Conf. Micro Electro Mech. Syst., no. February, pp. 488-491, 2012.

[89] L. Du, X. Zhu, and J. Zhe, "An inductive sensor for real-time measurement of plantar normal and shear forces distribution," IEEE Trans. Biomed. Eng., vol. 62, no. 5, pp. 1316-1323, 2015.

[90] H. Wang et al., "Design and Characterization of Tri-axis Soft Inductive Tactile Sensors," IEEE Sens. J., vol. 18, no. 19, pp. 77937801,2018

[91] S. Yeh and W. Fang, "Inductive Micro Tri-Axial Tactile Sensor Using a CMOS Chip with a Coil Array," IEEE Electron Device Lett., vol. PP, no. c, p. 1, 2019.

[92] Dan Mihai Stefa nescu and Mirela Adelaida Anghel, "Electrical methods for force measurement - A brief survey."

[93] G. de Boer et al., "Design Optimisation of a Magnetic Field Based Soft Tactile Sensor," Sensors, vol. 17, no. 11, p. 2539, 2017.

[94] S. Kärki, J. Lekkala, H. Kuokkanen, and J. Halttunen, "Development of a piezoelectric polymer film sensor for plantar normal and shear stress measurements," Sensors Actuators, A Phys., vol. 154, no. 1, pp. 57-64, 2009.

[95] M. Li, W. Cheng, J. Chen, R. Xie, and X. Li, "A High Performance Piezoelectric Sensor for Dynamic Force Monitoring of Landslide.," Sensors (Basel)., vol. 17, no. 2, Feb. 2017.

[96] T. C. Liang, J. J. Lin, and L. Y. Guo, "Plantar pressure detection with fiber bragg gratings sensing system," Sensors (Switzerland), vol. 16, no. 10, 2016.

[97] Z. F. Zhang, X. M. Tao, H. P. Zhang, and B. Zhu, "Soft fiber optic sensors for precision measurement of shear stress and pressure," IEEE Sens. J., vol. 13, no. 5, pp. 1478-1482, 2013.

[98] C. Tavares et al., "Gait shear and plantar pressure monitoring: A non-invasive OFS based solution for e-health architectures," Sensors (Switzerland), vol. 18, no. 5, 2018.

[99] M. F. Domingues et al., "Insole optical fiber sensor architecturefor remote gait analysis - an eHealth Solution," IEEE Internet Things $J$., vol. 4662, no. c, 2017. 
[100] W.-C. Wang, W. R. Ledoux, B. J. Sangeorzan, and P. G. Reinhall, "A shear and plantar pressure sensor based on fiber-optic bend loss," J. Rehabil. Res. Dev., vol. 42, no. 3, p. 315, 2005.

[101] W. C. Wang, W. R. Ledoux, C. Y. Huang, C. S. Huang, G. K. Klute, and P. G. Reinhall, "Development of a microfabricated optical bend loss sensor for distributive pressure measurement," IEEE Trans. Biomed. Eng., vol. 55, no. 2, pp. 614-625, 2008.

[102] C.-T. Chang, C. S. Liu, W. Soetanto, and W.-C. Wang, "A platformbased foot pressure/shear sensor," no. April 2012, p. 83481U, 2012.

[103] C.-S. Liu, G. W. Chou, X. Liang, P. G. Reinhall, and W.-C. Wang, "Design of a multi-layered optical bend loss sensor for pressure and shear sensing," no. April 2007, p. 65321P, 2007.

[104] W. Soetanto, N. T. Nguyen, and W.-C. Wang, "Fiber optic plantar pressure/shear sensor," no. March 2011, p. 79840Z, 2011.

[105] M. G. Xu, J.-L. Archambault, L. Reekie, and J. P. Dakin, "Discrimination between strain and temperature effects using dualwavelength fibre grating sensors," Electron. Lett., vol. 30, no. 13, pp. 1085-1087, 1994.

[106] I. Mohammad and H. Huang, "Pressure and Shear sensing based on a microstrip patch antenna," Meas. Sci. Technol., vol. 23, no. 10, 2012.

[107] I. Mohammad and H. Huang, "Shear sensing based on a microstrip patch antenna," Meas. Sci. Technol., vol. 23, no. 10, 2012.

[108] H. Huang, F. Farahanipad, and A. K. Singh, "A Stacked DuelFrequency Microstrip Patch Antenna for Simultaneous Shear and Pressure Sensing,” IEEE Sens. J., vol. 17, no. 24, p. 16978, 2017.

[109] T. Keatsamarn and C. Pintavirooj, "Foot plantar pressure measurement system using optical sensor," 2016.

[110] L. Shu, T. Hua, Y. Wang, Q. Qiao Li, D. D. Feng, and X. Tao, "Inshoe plantar pressure measurement and analysis system based on fabric pressure sensing array.," IEEE Trans. Inf. Technol. Biomed., vol. 14, no. 3, pp. 767-775, 2010.

[111] "pedar." [Online]. Available: http://novel.de/novelcontent/pedar. [Accessed: 17-Aug-2018].

[112] "F-Scan System | Tekscan." [Online]. Available: https://www.tekscan.com/products-solutions/systems/f-scan-system. [Accessed: 17-Aug-2018].

[113] A. B. Putti, G. P. Arnold, L. Cochrane, and R. J. Abboud, "The Pedar®in-shoe system: Repeatability and normal pressure values," Gait Posture, vol. 25, no. 3, pp. 401-405, 2007.

[114] "Evaluation and optimization of therapeutic footwear for neuropathic diabetic foot patients." .

[115] R. Waaijman, M. L. J. Arts, R. Haspels, T. E. Busch-Westbroek, F. Nollet, and S. A. Bus, "Pressure-reduction and preservation in custom-made footwear of patients with diabetes and a history of plantar ulceration," Diabet. Med., vol. 29, no. 12, pp. 1542-1549, 2012.

[116] A. L. Randolph, M. Nelson, S. Akkapeddi, A. Levin, and R. Alexandrescu, "Reliability of measurements of pressures applied on the foot during walking by a computerized insole sensor system," Arch. Phys. Med. Rehabil., vol. 81, no. 5, pp. 573-578, 2000.

[117] A. Amemiya et al., "Elevated plantar pressure in diabetic patients and its relationship with their gait features," Gait Posture, vol. 40, no. 3, pp. 408-414, 2014.

[118] “medilogic WLAN insole - medilogic." [Online]. Available: https://medilogic.com/en/medilogic-wlan-insole/. [Accessed: 17Aug-2018].

[119] "Instituto de Biomecánica - Biofoot/IBV. Sistema de plantillas instrumentadas para el análisis de las presiones plantares." [Online]. Available: https://www.ibv.org/productos-yservicios/productos/aplicaciones-biomecanicas/biofootibv-sistemade-plantillas-instrumentadas-para-el-analisis-de-las-presionesplantares. [Accessed: 17-Aug-2018].

[120] "WalkinSense - Kinematix SA.” [Online]. Available: http://www.vph-dare.eu/index.php/partner/to. [Accessed: 17-Aug2018].

[121] "W-INSHOE." [Online]. Available: https://www.medicapteurs.com/produits/winshoe-2/. [Accessed: 17Aug-2018].

[122] "Front page - Movesole." [Online]. Available: http://www.movesole.com/en/. [Accessed: 06-Sep-2018].

[123] C. Price, D. Parker, and C. Nester, "Validity and repeatability of three in-shoe pressure measurement systems," Gait Posture, vol. 46, pp. 69-74, 2016.

[124] “Moticon|Sensing Foot Dynamics." [Online]. Available: https://www.moticon.de/. [Accessed: 06-Sep-2018].

[125] "Footwork insole." [Online]. Available:

http://www.amcube.com/index.php/nos-

produits/podometre/footinsole. [Accessed: 06-Sep-2018].

[126] "Dynafoot 2." [Online]. Available:

http://www.technoconcept.fr/shop/gait-rehabilitation/26-http-

wwwtechnoconceptfr-shop-productphpidproduct $26 . \mathrm{html}$.

[Accessed: 06-Sep-2018].

[127] “LogR | Orpyx Medical Technologies.”[Online]. Available: http://orpyxlogr.orpyx.com/. [Accessed: 06-Sep-2018].

[128] "Sensor Medica web site - FlexInFit Sensorized Insoles." [Online]. Available:

https://www.sensormedica.com/site/en/products/sensorized-insoles. [Accessed: 06-Sep-2018].

[129] "Foot Insole Sensor System | Tactilus ${ }^{\circledR} . ”[$ Online]. Available: https://www.sensorprod.com/dynamic/foot-insole.php. [Accessed: 06-Sep-2018].

[130] A. Martínez-Nova, J. C. Cuevas-García, J. Pascual-Huerta, and R. Sánchez-Rodríguez, "BioFoot®in-shoe system: Normal values and assessment of the reliability and repeatability," Foot, vol. 17, no. 4, pp. 190-196, 2007.

[131] M. P. De Castro et al., "Accuracy and repeatability of the gait analysis by the walkinsense system," Biomed Res. Int., vol. 2014, 2014.

[132] L. Claverie, A. Ille, and P. Moretto, "Discrete sensors distribution for accurate plantar pressure analyses," Med. Eng. Phys., vol. 38, no. 12, pp. 1489-1494, 2016.

[133] K. S. Maluf, R. E. Morley, E. J. Richter, J. W. Klaesner, and M. J. Mueller, "Monitoring in-shoe plantar pressures, temperature, and humidity: Reliability and validity of measures from a portable device," Arch. Phys. Med. Rehabil., vol. 82, no. 8, pp. 1119-1127, 2001.

[134] M. Saito et al., "An in-shoe device to measure plantar pressure during daily human activity," Med. Eng. Phys., vol. 33, no. 5, pp. 638-645, 2011

[135] W. Xu, J. J. Liu, M.-C. Huang, L. He, N. Amini, and M. Sarrafzadeh, "Smart Insole : A Wearable System for Gait Analysis," Proc. 5th Int. Conf. Pervasive Technol. Relat. to Assist. Environ., pp. 1-4, 2012.

[136] O. Mazumder, A. S. Kundu, and S. Bhaumik, "Development of wireless insole foot pressure data acquisition device," Commun. Devices Intell. Syst. (CODIS), 2012 Int. Conf., pp. 302-305, 2012.

[137] H. Abou Ghaida, S. Mottet, and J. M. Goujon, "Plantar pressure cartography reconstruction from 3 sensors," Conf. Proc. ... Annu. Int. Conf. IEEE Eng. Med. Biol. Soc. IEEE Eng. Med. Biol. Soc. Annu. Conf., vol. 2014, pp. 578-581, 2014.

[138] A. Perrier et al., "Smart Diabetic Socks: Embedded device for diabetic foot prevention," Irbm, vol. 35, no. 2, pp. 72-76, 2014.

[139] Y. S. A. Mustufa, J. Barton, B. O’Flynn, R. Davies, P. McCullagh, and H. Zheng, "Design of a smart insole for ambulatory assessment of gait,” 2015 IEEE 12th Int. Conf. Wearable Implant. Body Sens. Networks, BSN 2015, 2015.

[140] K. Leemets, T. Terasmaa, P. Jaakson, A. Kume, and T. Tamm, "Development of A Smart Insole System for Gait and Performance Monitoring," Proc. 2015 Int. Conf. Mater. Sci. Appl., no. May 2016, 2015.

[141] S. Rajala, T. Salpavaara, and S. Tuukkanen, "Testing and comparing of film-type sensor materials in measurement of plantar pressure distribution," Proc. Annu. Int. Conf. IEEE Eng. Med. Biol. Soc. EMBS, vol. 2016-Octob, pp. 251-254, 2016.

[142] A. Amemiya, H. Noguchi, M. Oe, H. Sanada, and T. Mori, "Establishment of a measurement method for in - shoe pressure and shear stress in specific regions for diabetic ulcer prevention," Conf Proc IEEE Eng Med Biol Soc, vol. 2016, pp. 2291-2294, 2016.

[143] H. H. Huang, W. R. Cheng, G. R. Chen, and L. Y. Shyu, "Portable Bluetooth Low Energy System for Synchronize Foot Pressure Measurement," no. Gcce, pp. 1-2, 2017.

[144] M. F. Domingues et al., "Insole optical fiber Bragg grating sensors network for dynamic vertical force monitoring," J. Biomed. Opt., vol. 22, no. 9, p. 091507, 2017.

[145] K. Deschamps and B. Messier, "Pressure reducing capacity of felt: A feasibility study using a new portable system with thin sensors," Diabetes Res. Clin. Pract., vol. 107, no. 3, pp. e11-e14, 2015.

[146] J. Coates, A. Chipperfield, and G. Clough, "Wearable Multimodal Skin Sensing for the Diabetic Foot," Electronics, vol. 5, no. 3, p. 45, 
2016.

[147] T. Mori, M. Hamatani, H. Noguchi, M. Oe, and H. Sanada, "InsoleType Simultaneous Measurement System of Plantar Pressure and Shear Force During Gait for Diabetic Patients,” vol. 24, no. 5, 2012.

[148] P. Salvo et al., "Temperature-and $\mathrm{pH}$-sensitive wearable materials for monitoring foot ulcers," Int. J. Nanomedicine, vol. 12, pp. 949954, 2017.

[149] G. Gethin et al., "Monitoring of $\mathrm{pH}$ and temperature of neuropathic diabetic and nondiabetic foot ulcers for 12 weeks: An observational study," Wound Repair Regen., pp. 1-6, 2018.

[150] C. McArdle, K. Lagan, S. Spence, and D. McDowell, "Diabetic foot ulcer wound fluid: the effects of $\mathrm{pH}$ on DFU bacteria and infection," J. Foot Ankle Res., vol. 8, no. S1, p. A8, 2015.

[151] P. W. Brand, "Tenderizing the Foot," Foot Ankle Int., vol. 24, no. 6, pp. 457-461, Jun. 2003.

[152] M. Yavuz et al., "Temperature as a predictive tool for plantar triaxial loading," J. Biomech., vol. 47, no. 15, pp. 3767-3770, Nov. 2014. 